\title{
USGS Cascades Volcano Observatory News Media Management Guide-General Protocols and Templates
}

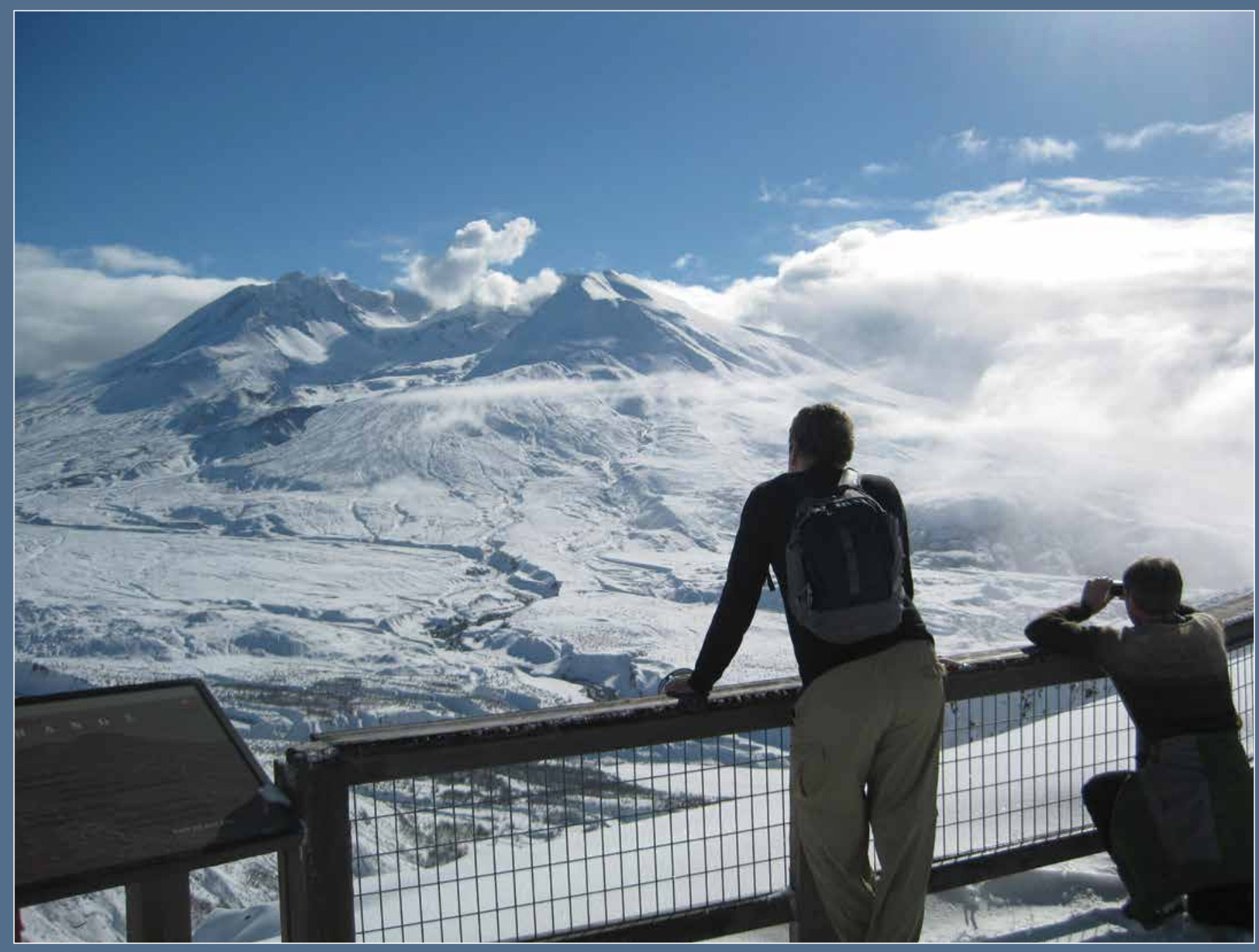

Circular 1462

U.S. Department of the Interior U.S. Geological Survey 



\section{USGS Cascades Volcano Observatory News Media Management Guide-General Protocols and Templates}

By Carolyn L. Driedger and Elizabeth G. Westby

Circular 1462 


\title{
U.S. Department of the Interior DAVID BERNHARDT, Secretary
}

\author{
U.S. Geological Survey \\ James F. Reilly II, Director
}

U.S. Geological Survey, Reston, Virginia: 2020

For more information on the USGS - the Federal source for science about the Earth, its natural and living resources, natural hazards, and the environment-visit https://www.usgs.gov or call 1-888-ASK-USGS.

For an overview of USGS information products, including maps, imagery, and publications, visit https://store.usgs.gov.

Any use of trade, firm, or product names is for descriptive purposes only and does not imply endorsement by the U.S. Government.

Although this information product, for the most part, is in the public domain, it also may contain copyrighted materials as noted in the text. Permission to reproduce copyrighted items must be secured from the copyright owner.

Suggested citation:

Driedger, C.L., and Westby, E.G., 2020, USGS Cascades Volcano Observatory news media management guide-

General protocols and templates: U.S. Geological Survey Circular 1462, 53 p., https://doi.org/10.3133/cir1462.

ISSN 1067-084X (print)

ISSN 2330-5703 (online)

ISBN 978-1-4113-4374-0

Cover: Mount St. Helens continues to attract news media, the public, and scientists from around the world even decades after the May 18, 1980 catastrophic eruption. This photograph was taken on the patio of the Johnston Ridge Observatory, Mount St. Helens National Volcanic Monument. USGS photograph by Larry Mastin, February 8, 2011. 


\section{Preface}

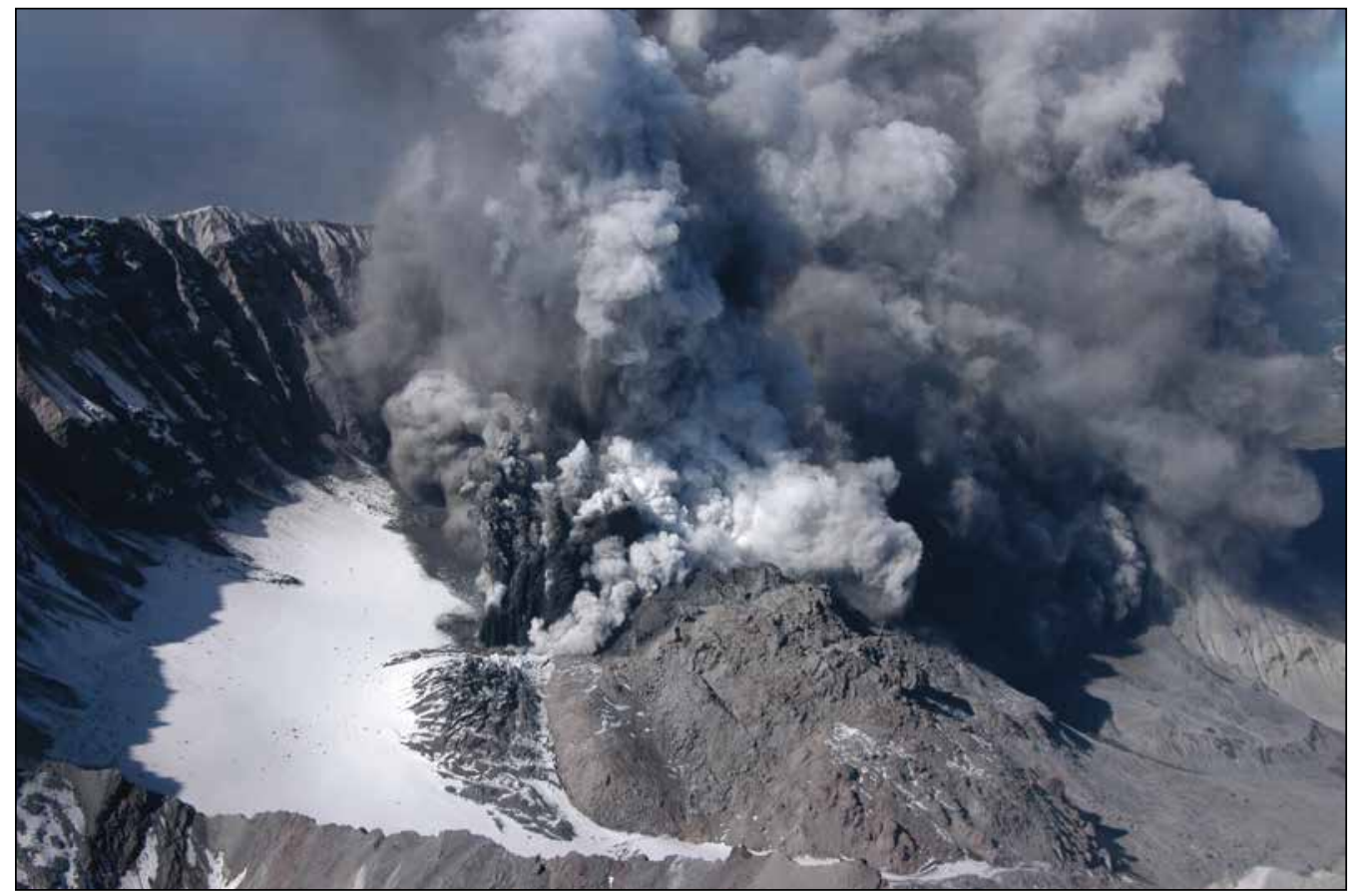

Aerial view of one of the first steam and ash explosions in the crater of Mount St. Helens, Washington, on October 1, 2004. USGS photograph by John Pallister.

In October 2004, Mount St. Helens volcano reawakened with spectacular blasts of ash and steam before settling into 40 months of continuous lava dome growth on the crater floor. The impact of the eruption on the landscape beyond the vent area was minimal and no human populations were at serious risk. Yet, the news media's demands for information created a communications crisis for scientists during the early phases of the eruption, requiring as much or more attention than that required for volcano monitoring and analysis.

Approximately two dozen scientific colleagues from other U.S. Geological Survey (USGS) volcano observatories came to the aid of staff at the USGS Cascades Volcano Observatory (CVO) and half of them assisted with the news media response. For eleven days a Joint Information Center, consisting mostly of regional non-USGS public information specialists, aided the response. Scientists conducted interviews and press conferences, wrote news releases, and answered phones, providing critical and necessary information to the media and the public. There was a broad sense among staff of their professional responsibility to communicate effectively with the news media. After all, if they did not speak on subjects for which they had direct experience and professional familiarity, who would do so?

The 2004-2008 eruption response taught CVO staff that (1) addressing the needs of the news media can require as much (or possibly more) attention than monitoring an erupting volcano; (2) with great rapidity, an observatory can be overwhelmed by the news media, requiring the help of other observatories and agencies; (3) multi-agency pre-crisis planning for news media communication is an essential component of an effective news media response; (4) we must 
understand the needs of the news media to improve the efficiency of information delivery; (5) CVO specialists from a variety of disciplines must dedicate time to creating social and visual media and geospatial data to meet the increasingly sophisticated needs and expectations of the news media and the public; and 6) pre- and post-crisis trainings, protocols, and guidelines can help staff and guest scientists prepare for future media interactions.

The trusting working relationships established with regional news media during the 2004-2008 eruption have continued during times of relative calm. Ongoing communication between the news media and CVO staff familiarizes the news media with USGS protocols, science methodology, and volcano terminology and helps scientists to understand the needs of the news media. It builds trust and transparency and improves the odds that our science will be communicated accurately and shared broadly in times of crisis. Additionally, communications staff work with external agency partners to develop plans for coordinating communication during times of intense news media interest

Observatory communications specialists developed this news media management guide during the decade after the 2004-2008 eruption of Mount St. Helens and refined it after engaging in numerous smaller news media interactions. It is a living document and the protocols and message delivery mechanisms within it have and will evolve with time. The underlying tenets, however, will remain the same - the need for physical preparations, for effective messaging that conveys facts and their relevance, and the need to build and maintain trusting working relationships with the news media before, during, and after a crisis.

This document can be used to help set up a communications team (Appendix 1. CVO Personnel and Other Contact Information); determine primary objectives (Appendix 2. Single Overriding Communication Objective Worksheet); develop a communication plan (Appendix 3. Communication Plan Template); prepare talking points and visuals (Appendix 4. Talking Points and Key Messages); issue a news release (Appendix 5. Examples of News Releases); work with the news media (Appendix 6. General Guidance for Working with News Media); respond to difficult questions (Appendix 7. Covello's Risk Communication Templates); track documentary producer requests (Appendix 8. Documentary Request Form); use a website to convey information (Appendix 9. General Guidance Regarding the U.S. Geological Survey Cascades Volcano Observatory Website); develop content for social media (Appendix 10. General Guidance for Working with Social Media); and put together a quick response template for the first few hours to days of a crisis (Appendix 11. Volcano Science Center Rapid Reference Guide). The effort put into developing a communication program now can improve the likelihood of a practiced and coordinated news media response during the next volcanic crisis. 


\section{Contents}

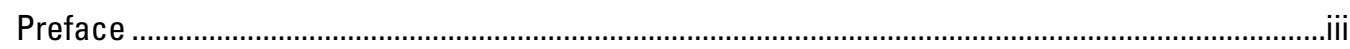

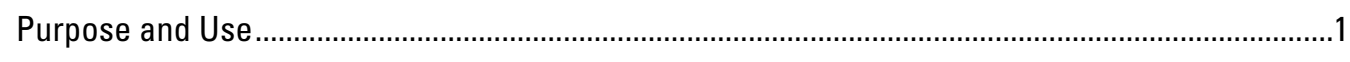

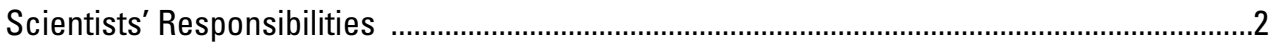

Responding in a Timely Manner ................................................................................. 2

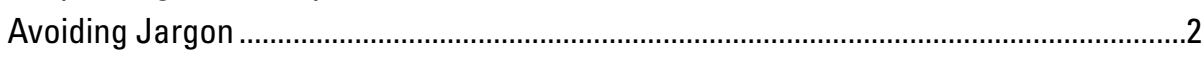

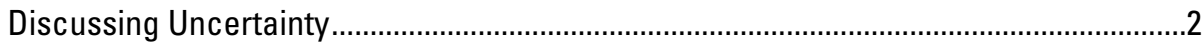

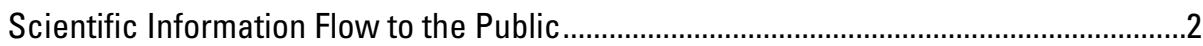

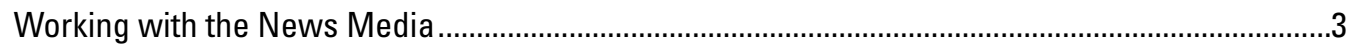

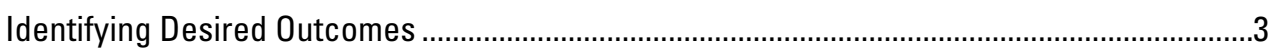

Assembling Tools for Working with the News Media..............................................................

Developing Communication Plans ...........................................................................................

Using Multiple Communications Products ………………...........................................................

News Releases and Advisories for High-Profile Products or Events ................................5

Websites and Social Media for Volcano Information.........................................................

Training for Communication During Crises ...........................................................................

Training for News Media ..............................................................................................

Training for CVO Staff....................................................................................................

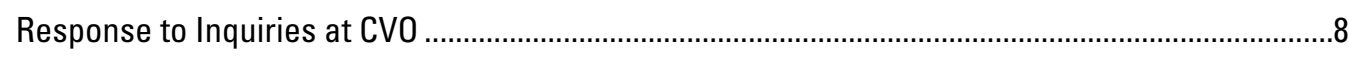

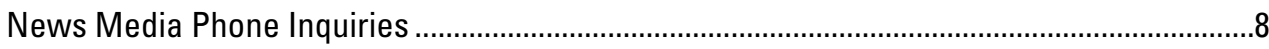

News Media Emails, Webmaster Inquiries, and Social Media Comments .............................8

Documentary Production Company Requests ..........................................................................

Documentary Request Form ..................................................................................

Commercial Release Forms ...................................................................................

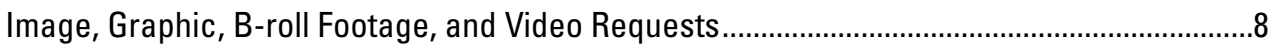

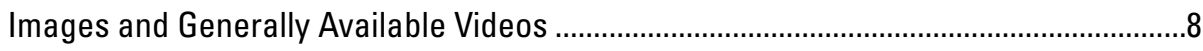

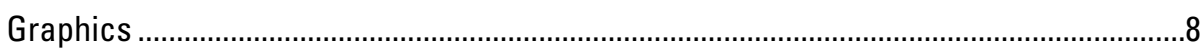

B-roll and Archival Footage ....................................................................................

Providing Large-File Images and Graphics to the Public .................................................

Geospatial Data and Products..........................................................................................

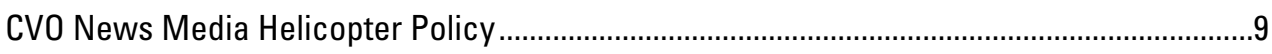

Response to Intense Media Interest ......................................................................................11

Developing Products and Messages ............................................................................11

Preparation of Talking Points; Rapid Coordination of Message Development................11

Parallel Communication................................................................................................12

External Partners …….......................................................................................

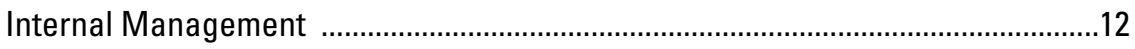

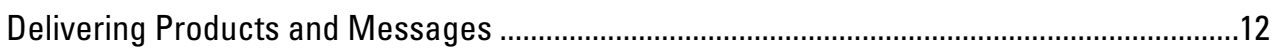

News Media Briefings (Press Conferences) ................................................................13

Media Days and Group Interviews ..........................................................................

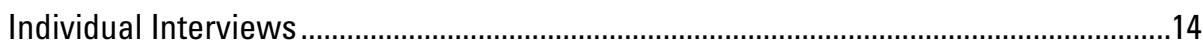

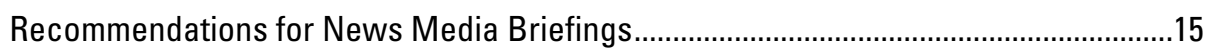

Participation at Public Meetings ..................................................................................16 
Communication Duties During Intense Media Interest (no formal JIC) .................................16

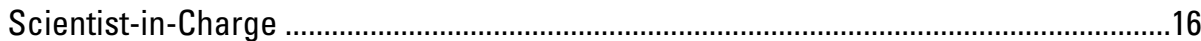

Communications Coordinator ....................................................................................16

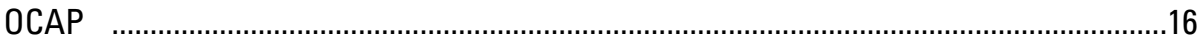

VHP Social Media Ambassadors and Website Personnel ..................................................17

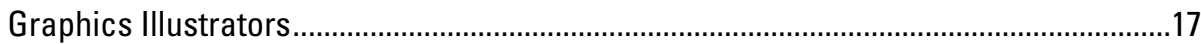

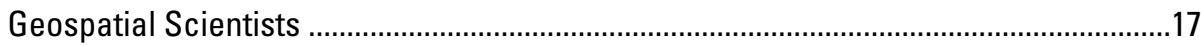

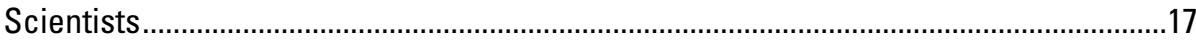

Multi-Agency Response with an Incident Command Joint Information Center or System ............18

Communication Duties In Support of the JIC or JIS ........................................................19

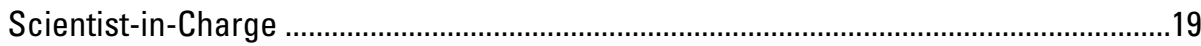

Communications Coordinator ...................................................................................

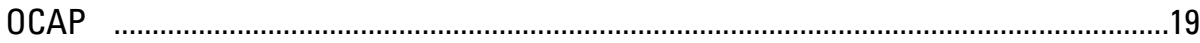

VHP Social Media Ambassadors and Website Personnel ..............................................19

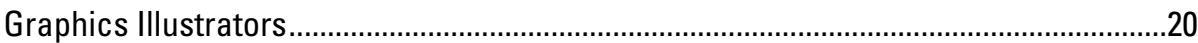

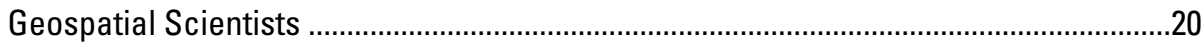

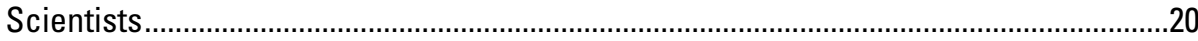

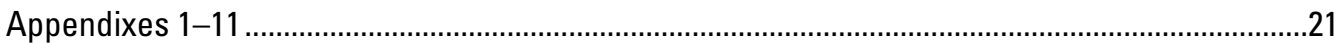

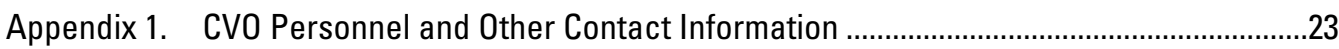

Appendix 2. Single Overriding Communication Objective Worksheet ..........................................25

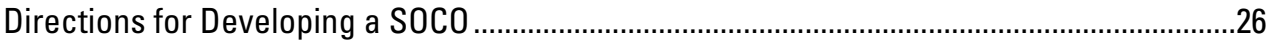

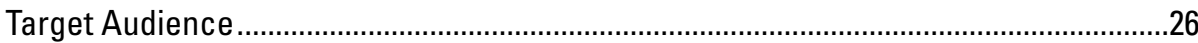

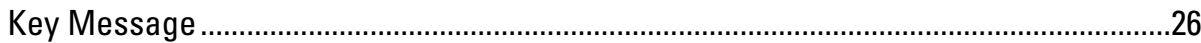

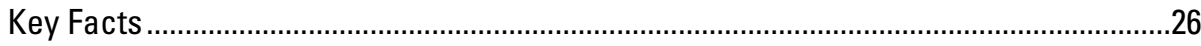

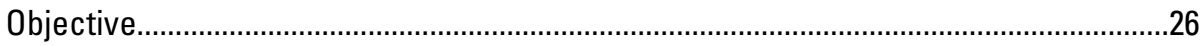

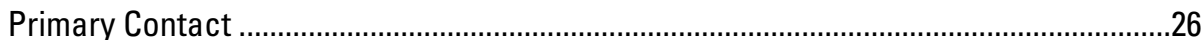

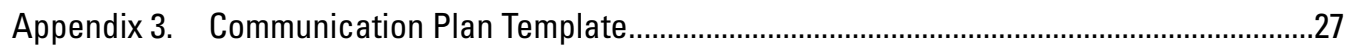

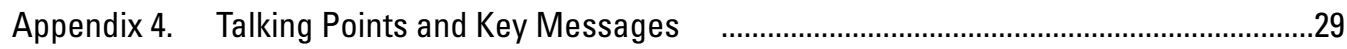

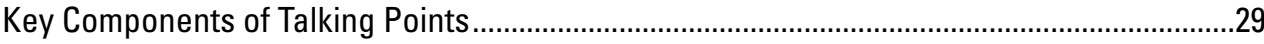

Eruption and Hazards Messages ...........................................................................................29

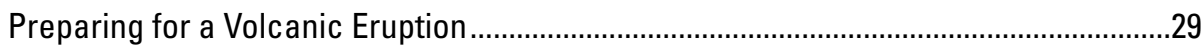

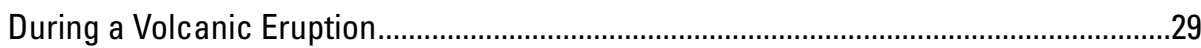

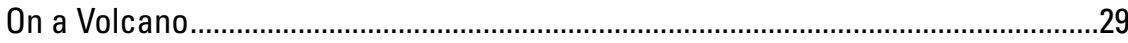

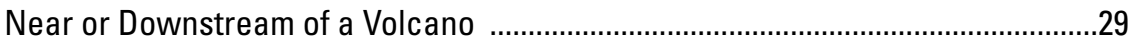

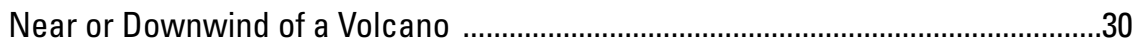

After a Volcanic Eruption.........................................................................................

Volcano Science Center Key Messages..............................................................................30

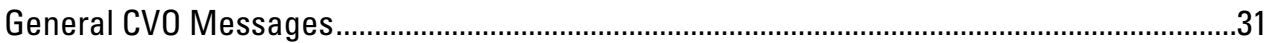

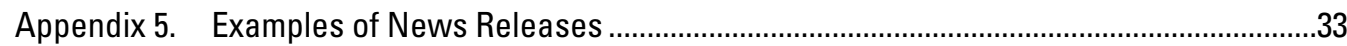

Sample of a News Release that Might Accompany an Official Alert Level Change ...............33

Example of a News Release that Describes Ongoing Activity, Hazards, and

Role of the USGS 
Appendix 6. General Guidance for Working with News Media.....................................................

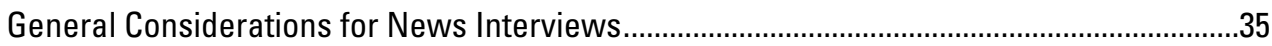

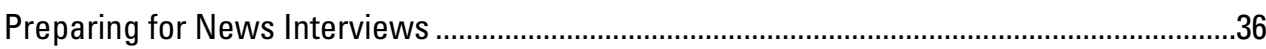

Your news interview will benefit from careful attention to messaging and presentation.

Some general considerations for preparing for news interviews are as follows: ....36

Developing Content for News Interviews .............................................................................37

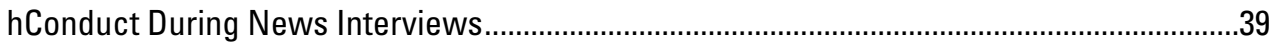

After the News Interview ........................................................................................... 40

News Interviews Involving Multiple Agencies ...................................................................40

Appendix 7. Covello's Risk Communication Templates ................................................................4

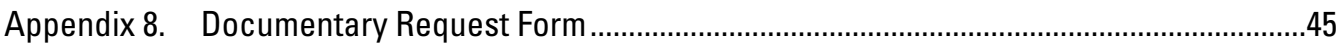

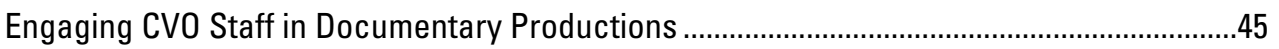

Appendix 9. General Guidance Regarding the U.S. Geological Survey Cascades Volcano

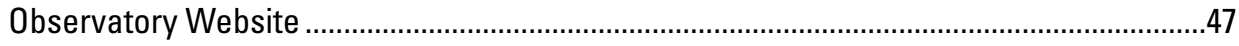

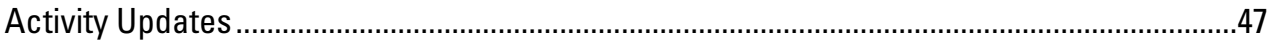

News Current Events and Volcano Hazards Program News ..................................................4

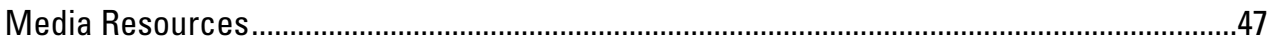

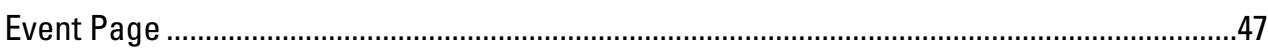

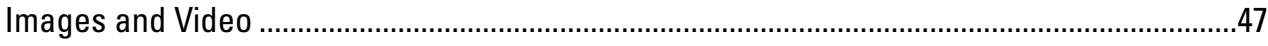

Responding to Webmaster Inquiries ..............................................................................

Appendix 10. General Guidance for Working with Social Media .................................................49

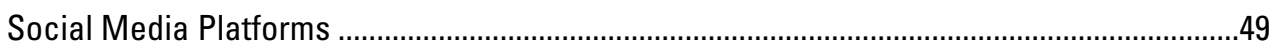

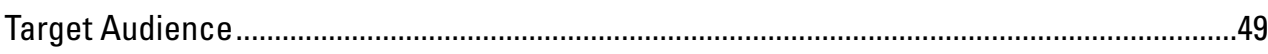

Social Media Ambassadors ............................................................................................ 49

Social Media Posts—Content Creation .............................................................................4

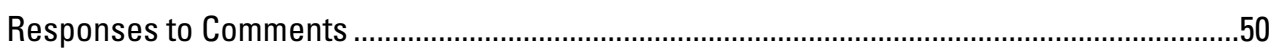

Appendix 11. Volcano Science Center Rapid Reference Guide ..................................................51

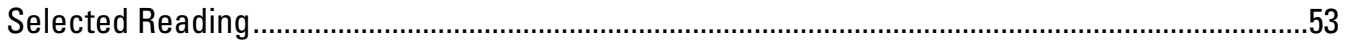




\section{Abbreviations}

CVO USGS Cascades Volcano Observatory

DOI U.S. Department of the Interior

FAQ frequently asked question

FEMA Federal Emergency Management Agency

GIS geographic information system

JIC joint information center

JIS joint information system

MAC multiagency coordination

NIMS National Incident Management System

OAS DOI Office of Aviation Services

OCAP Office of Communications and Publishing

OEM Oregon Office of Emergency Management

PIO public information officer

RDPO Portland Oregon's Regional Disaster Preparedness Organization

SOCO single overriding communication objective

USGS U.S. Geological Survey

VAN Volcano Activity Notice

VHP USGS Volcano Hazards Program

VNS USGS Volcano Notification Service

VONA Volcano Observatory Notice for Aviation

VSC USGS Volcano Science Center

WEPIN Washington State Emergency Public Information Network

WEMD Washington Emergency Management Division 


\title{
USGS Cascades Volcano Observatory News Media Management Guide-General Protocols and Templates
}

\author{
By Carolyn L. Driedger and Elizabeth G. Westby
}

"We must couch our discussion in terms that have meaning for the communities we are engaging. Only then can our science be put to use for the benefit of society and subsequently be appreciated, supported, and sustained."

9

—Dork Sahagian, Journal of Geophysical Research Biogeosciences (Sahagian, 2016).

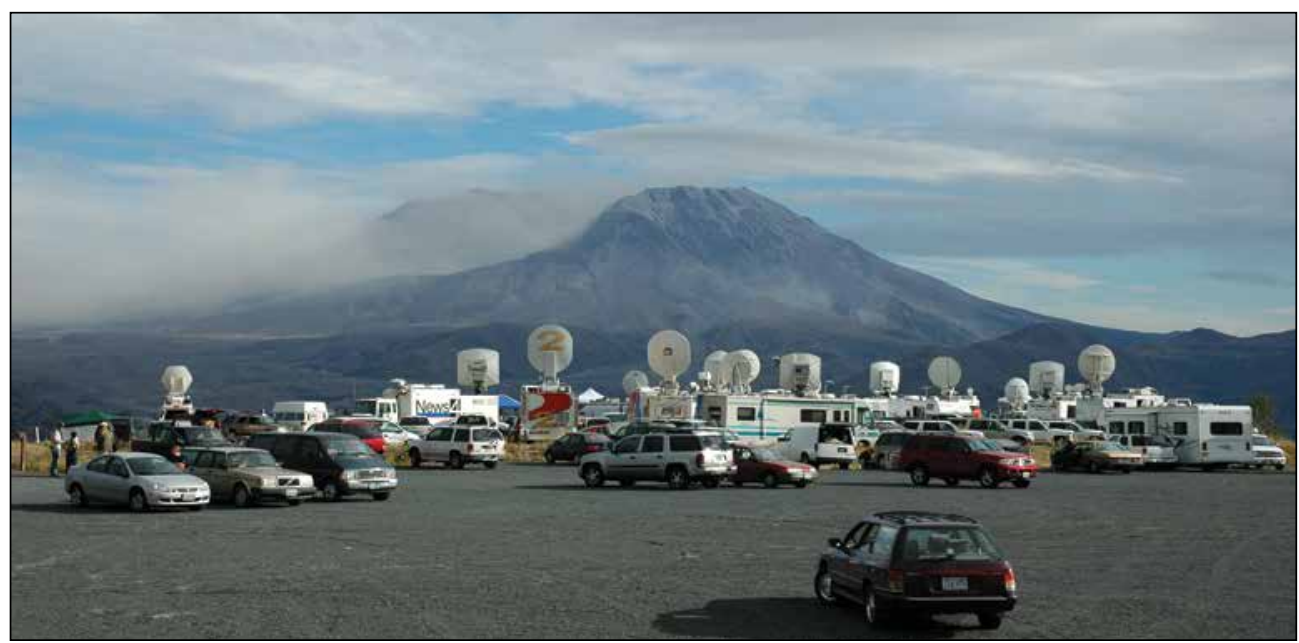

Members of the news media gather at the Castle Lake viewpoint near Mount St. Helens, Washington, necessitating scientific staff to be present at both the U.S. Geological Survey Cascades Volcano Observatory in Vancouver, Washington, and the volcano. USGS photograph by Larry Mastin, October 5, 2004.

\section{Purpose and Use}

This guide describes general protocols and provides templates for news media management at the U.S. Geological Survey (USGS) Cascades Volcano Observatory (CVO) and is intended for use by the CVO scientist-in-charge, communications staff, scientists, and guest communications colleagues. This public version, with CVO names and contact information removed, may be useful to other agencies developing their own protocols and templates.

This guide evolved from a smaller document hastily assembled out of necessity during the complex and overwhelming news media interest in the 2004-2008 Mount St. Helens eruption. News media interest exceeded the need for life-saving crisis communication and foretold of the need for future multi-faceted and well-coordinated news media and social media responses during future volcanic events. This guide accompanies the USGS Volcano Science Center's (VSC's) general guidelines and protocols for how communications staff at all VSC observatories will work together to respond to news media requests. The protocols and templates are applicable to (1) normal conditions when CVO has an opportunity to be proactive with its messages and to raise general awareness, (2) general responses to news media and TV documentary inquiries, (3) intense news media interest where the responsibility to communicate information and hazards rests primarily with staff at CVO, and (4) intense and overwhelming news media interest that requires a multiagency response. This guide reflects general protocols in effect at the time of publication. The information will be modified as conditions change. Although "news media" generally refers to traditional outlets such as $\mathrm{TV}$, radio, and newspapers, the protocols used to engage these traditional outlets apply also when responding to bloggers, online news services, and social media comments.
"The media are a sort of information utility serving up a small but steady stream of science news, and the scientists who appear in quotes or sound bites or behind the scenes as crucial sources of information are the fuel." - Hays and Grossman, 2006 


\section{Scientists' Responsibilities}

Members of the news media generally want to speak to scientists and not those who manage access to them. It is the responsibility of the interviewee to be knowledgeable about the scientific content as well as CVO's role within the larger VSC and to present the information in an understandable manner.

\section{Responding in a Timely Manner}

In the current 24-hour-a-day news world, reporters often work on short deadlines. It is a scientist's responsibility to return calls or emails as soon as possible. Interviews, whether for film or television documentaries or the media, require some pre-planning and coordination with scientific colleagues and CVO communications staff regarding messaging. For purposes of coordination, it is a good idea for scientists to notify communications staff and the scientist-incharge regarding requests.

\section{Avoiding Jargon}

A recurrent critique of science communication is how frequently scientific jargon is used instead of terms in common usage by the public. When we talk to scientific colleagues, we have the luxury of using technical terminology. When speaking to the news media and public, we lose that common understanding and need to make adjustments.
"Leading with what is known and highlighting the societal implications with multiple examples will increase the chances of your science being understood and used." —Milch and others, 2019

We must explain ourselves and our work with concise words that others can understand and find relevant to their lives. A variety of websites, such as the website of the American Geophysical Union (https://www.agu.org/Share-and-Advocate/Share/News-media/Jargon), discuss scientific jargon and how to identify and replace it. A straightforward way to identify jargon is to ask a public information officer from another agency about which terms they don't understand and make adjustments. You can increase the number of people who are interested in your subject by analyzing word usage before speaking and by keeping the message simple, to the point, and relevant to the audience.

"The uncertainty of when a hazard will occur can make the hazard seem unworthy of attention. Focus instead on the impact, which is easier to convey and can be more engaging and motivating. One way to focus on the impact without ignoring uncertainty would be, 'Our best estimate is that a geomagnetic storm causing damage $\mathrm{x}, \mathrm{y}$, and $\mathrm{z}$ will occur sometime within w years; the worst-case scenario is... and the best-case scenario is..."'

-Milch and others, 2019

\section{Discussing Uncertainty}

The news media and public do not always understand the difference between scientific uncertainty and scientific ignorance. Introduce them to uncertainty while you tell them about hazards, well in advance of a volcano reawakening. Explain the sources of uncertainty often. This helps the news media and public understand why scientists are not telling them exactly when an eruption will occur, how powerful it will be, or the precise area that will be impacted. (See guidance for creating talking points in appendix 4 and conducting interviews in appendix 6. .)

"Start with what you know and stick with the main point(s) you want to convey. This contrasts with traditional scientific communication in academic journals and presentations, which begins by providing context and describing what is not known." -Milch and others, 2019

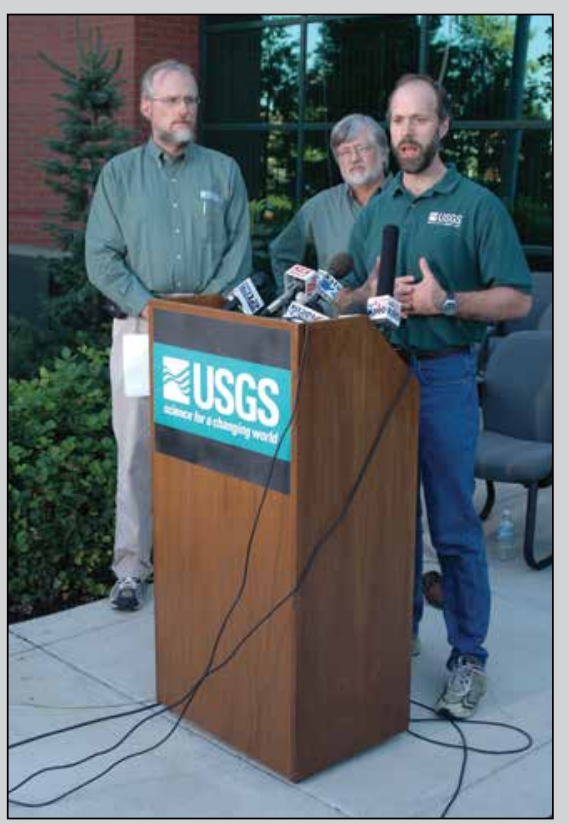

U.S. Geological Survey Cascades Volcano Observatory seismologist Seth Moran speaks to the news media about volcano seismicity. USGS photograph by David Wieprecht, October 4, 2004.

\section{Scientific Information Flow to the Public}

The information needs of the news media and public are different from the needs of scientific journals. This requires that $\mathrm{CVO}$ couch facts in context by showing the relevance of the information and addressing the societal implications instead of solely focusing on transmittal of scientific facts. It might require science and communications staff to invert the scientific style of presenting the unknown and data first, followed by conclusions. A more accessible flow of information begins with conclusive statements, which are then supported with data and evidence. CVO staff are encouraged to speak in a narrative style about the potential cascading series of eruption processes and impacts. 


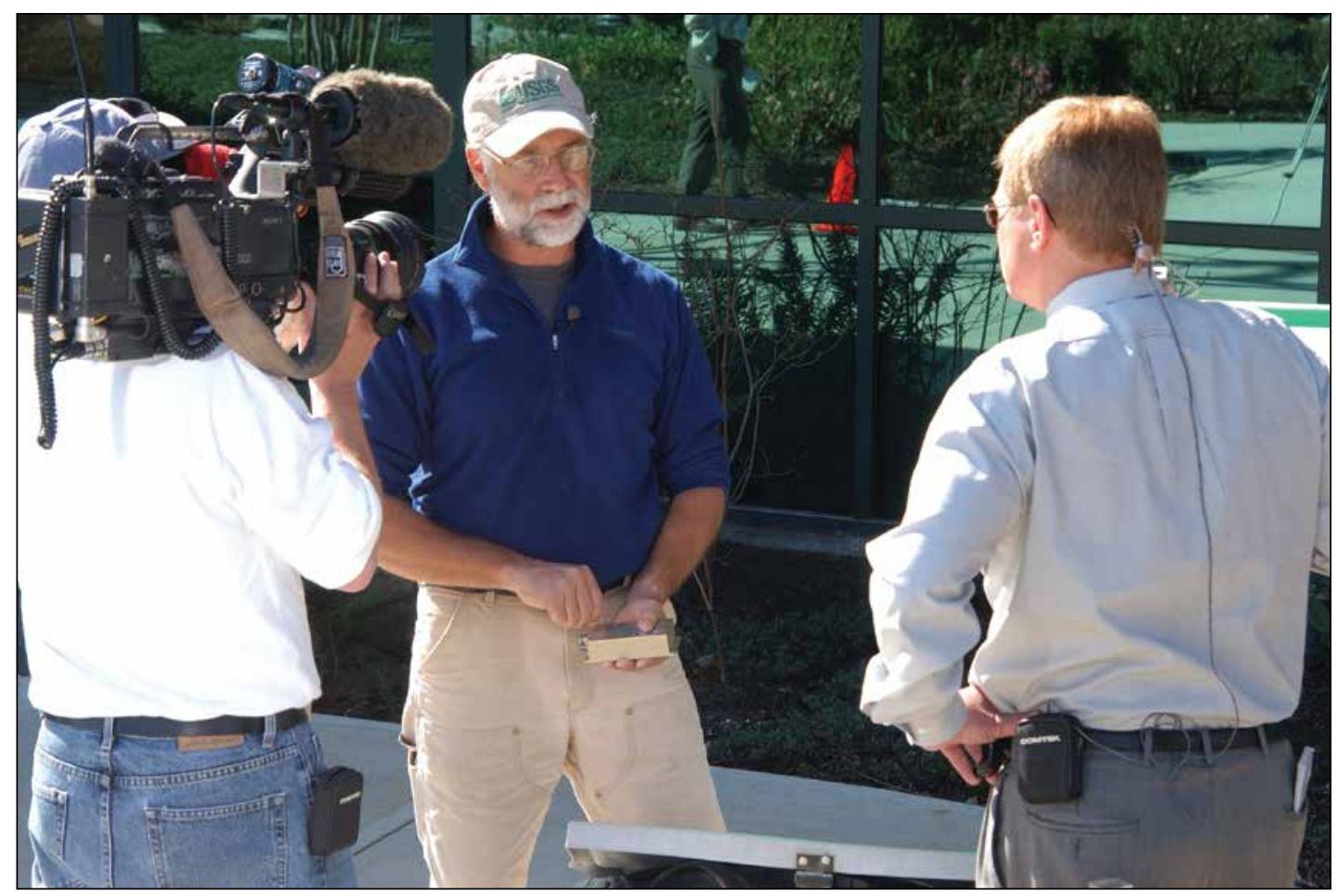

A U.S. Geological Survey scientist answers questions about remote monitoring technology used at active volcanoes. USGS photograph by David Wieprecht, March 10, 2005.

\section{Working with the News Media}

Explaining science to the public through the news media can be challenging. The news media often operates on short deadlines and is perceived as wanting only short, attentiongrabbing headline stories. Yet, the news media may be the principal source from which the public receives science information. Although it isn't always easy, reporter-scientist interactions can offer the best opportunity for the rapid and efficient delivery of information to the public and can be the best antidote to incorrect reporting.

\section{Identifying Desired Outcomes}

Desired outcomes for working with the news media comply with requirements for USGS Scientific Integrity Principles by "communicating the results of scientific activities clearly, honestly, objectively, thoroughly, accurately, and in a timely manner" (https://www.usgs.gov/about/organization/sciencesupport/survey-manual/50025-scientific-integrity). The desired outcomes are as follows:

- CVO maintains a reputation as "the" reliable source of relevant and timely information about the status of volcano hazards in the United States that addresses the interests and inquiries of the news media.

- An informed news media has the information necessary to develop accurate news stories for the public.
- An informed and coordinated national emergency management and response network can effectively manage news media interests about volcano hazards.

- The public supports ongoing work by CVO as reported on by the news media and in social media.

- CVO staff use news media document templates that promote efficient delivery of messaging to the news media.

These desired outcomes lay the foundation for a multi-modal approach to communication that also includes USGS websites, social media, and general public outreach.

\section{Assembling Tools for Working with the News Media}

Science isn't "done" until it is shared. CVO communications staff proactively work with its management and scientists to identify upcoming research results, new publications, special events, and volcano news for dissemination to web pages, social media, and the news media. Together, they develop a strategy for posting analyses of complex issues that can inform the public, preempt development of misperceptions, and raise the visibility of USGS work.
"Keep the story going and you can keep the flow of information going... forever. sion series is - an ongoing story, week after week, feeding you information about the characters and story." -Olson, 2009 That's what a good televi- 


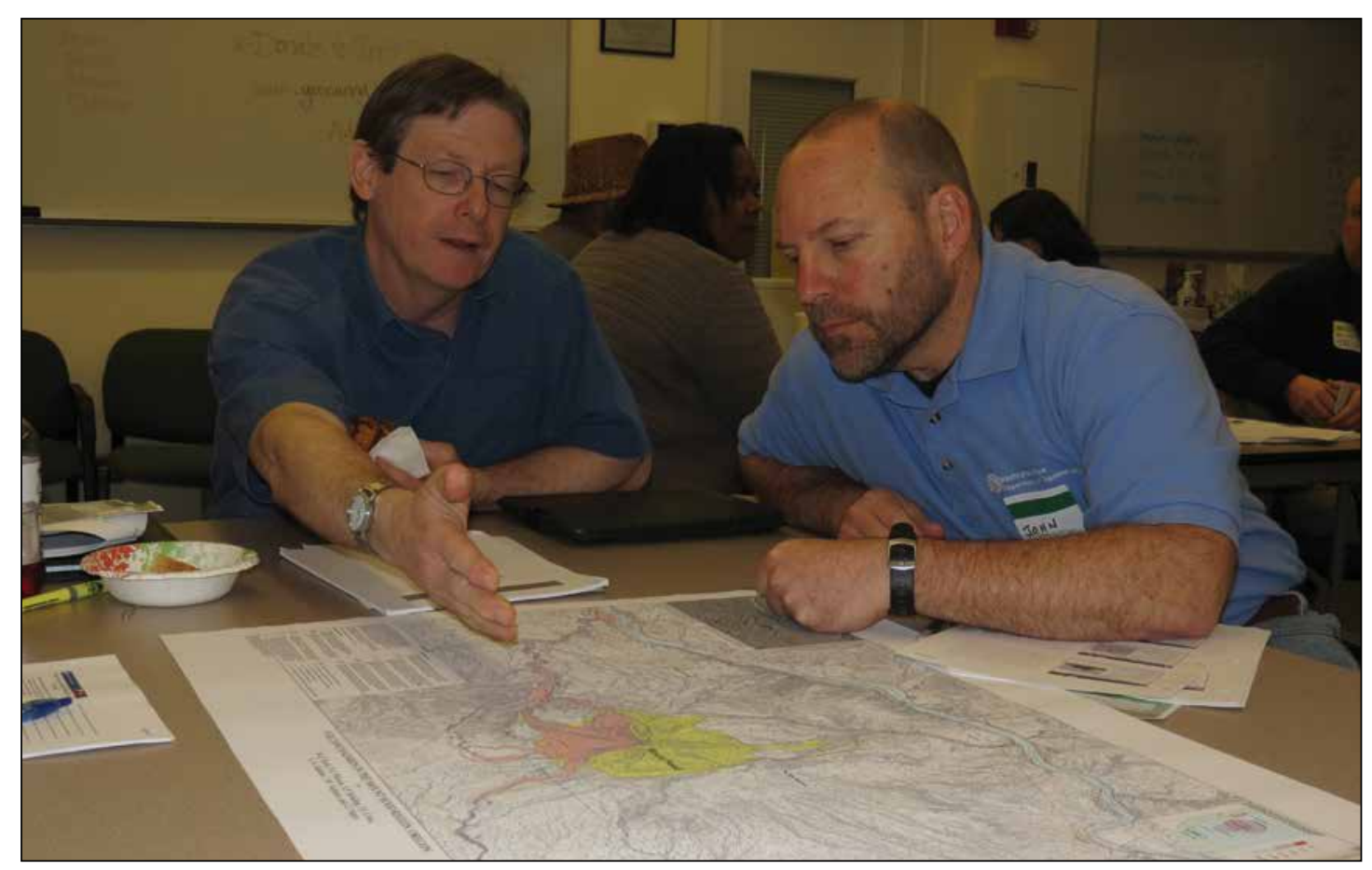

U.S. Geological Survey staff and agency partners participate regularly in volcano trainings and in developing and exercising emergency coordination plans. This frequent contact helps staff members in all involved agencies build and maintain collegial relationships and readiness for hazardous volcanic activity. USGS photograph by Carolyn Driedger, March 12, 2014.

\section{Developing Communication Plans}

For specific events and information releases that will be of interest to the news media, CVO develops informal short- and long-term communication plans internally and with external partners to promote general coordination and consistent messaging. As described in greater detail in appendixes $2-4$, communication plans prepared by $\mathrm{CVO}$ and its partners contain interagency contact lists, plans, and schedules for news media releases and media events; talking points, which ensapsulate messages; strategies for reaching media and interacting with the public; and actions to take from first response to establishing a joint information center (JIC) or joint information system (JIS).

The following steps are best practices for developing communication plans:

1. Identify partners who have similar vested interests, and with whom you can develop audience-appropriate communication strategies, key messages, and preferred outcomes.

2. Identify the topics of concern to principal audiences. Audiences can include affected communities, other agencies, news media, National Park or Forest Service interpretive staff, Congress, local officials, and others.

3. Develop audience-appropriate messaging for all affected groups.
4. Develop messages that include the information to be released and its relevance (the "so what" factor), context, and implications, both scientifically and to the information user.

5. Ensure that messaging is agreed upon and understood among all spokespeople so that there is consistency in information delivery. This is often called "speaking with one voice."

6. Consider a broad range of options for releasing products or providing services such as news media releases, information statements, visitor area signage and handouts, website and social media posts, news media briefings (by telephone or in person), and media days in the field.

7. Creating a timeline, work plan, and contact list of all people involved. Test communication plans during volcano coordination plan exercises.

8. Develop a paper or digital press kit that includes news releases, statistics, images, and other pertinent resources.

9. Monitor results as you implement the plan.

10. Evaluate the effectiveness of the messaging and make adjustments to your wording as necessary with the goal of communicating important information simply and clearly. 


\section{Using Multiple Communications Products}

CVO provides routine information about the behavior of volcanoes to the public and news media through the Volcano Notification Service (VNS), current News events posts on the $\mathrm{CVO}$ website, social media, and news media releases and advisories (see table 1). CVO uses these mechanisms during periods of intense media interest with more frequent updates as the situation warrants.

\section{News Releases and Advisories for High-Profile Products or Events}

News media releases and advisories announce the latest high-profile products, services, research results, and public events such as open houses. They are written by CVO staff in conjunction with the USGS Office of Communications and Publishing (OCAP), which also is responsible for review, approval, online posting, and dissemination. Joint news releases with other agencies are drafted with input from CVO and must also be submitted to OCAP for review and approval. The OCAP approval process may take weeks, although the process can be expedited when health and safety are at risk. News media products are distributed to the news media and also posted and archived on the USGS News Releases website, at: https://www.usgs.gov/news/news-releases.

Appendix 5 offers a model of a news release for a change in volcano alert level and a news release that describes ongoing activity, hazards, and the role of the USGS in monitoring volcanic activity and providing timely warnings to communities and civil authorities.

\section{Websites and Social Media for Volcano Information}

Websites and social media offer online locations for immediate access to all types of volcano information. USGS social media ambassadors, communications staff, and scientists develop content for USGS websites and social media accounts. Content can include short versions of news media releases and advisories, official volcano alerts and information statements, changes in status, and general volcano information (see appendixes 9 and 10 for more details). CVO communications staff post videos to social media, the CVO website, the USGS Multimedia Gallery (https://www.usgs. gov/products/multimedia-gallery/overview), and the USGS YouTube Channel (https://www.youtube.com/user/usgs).

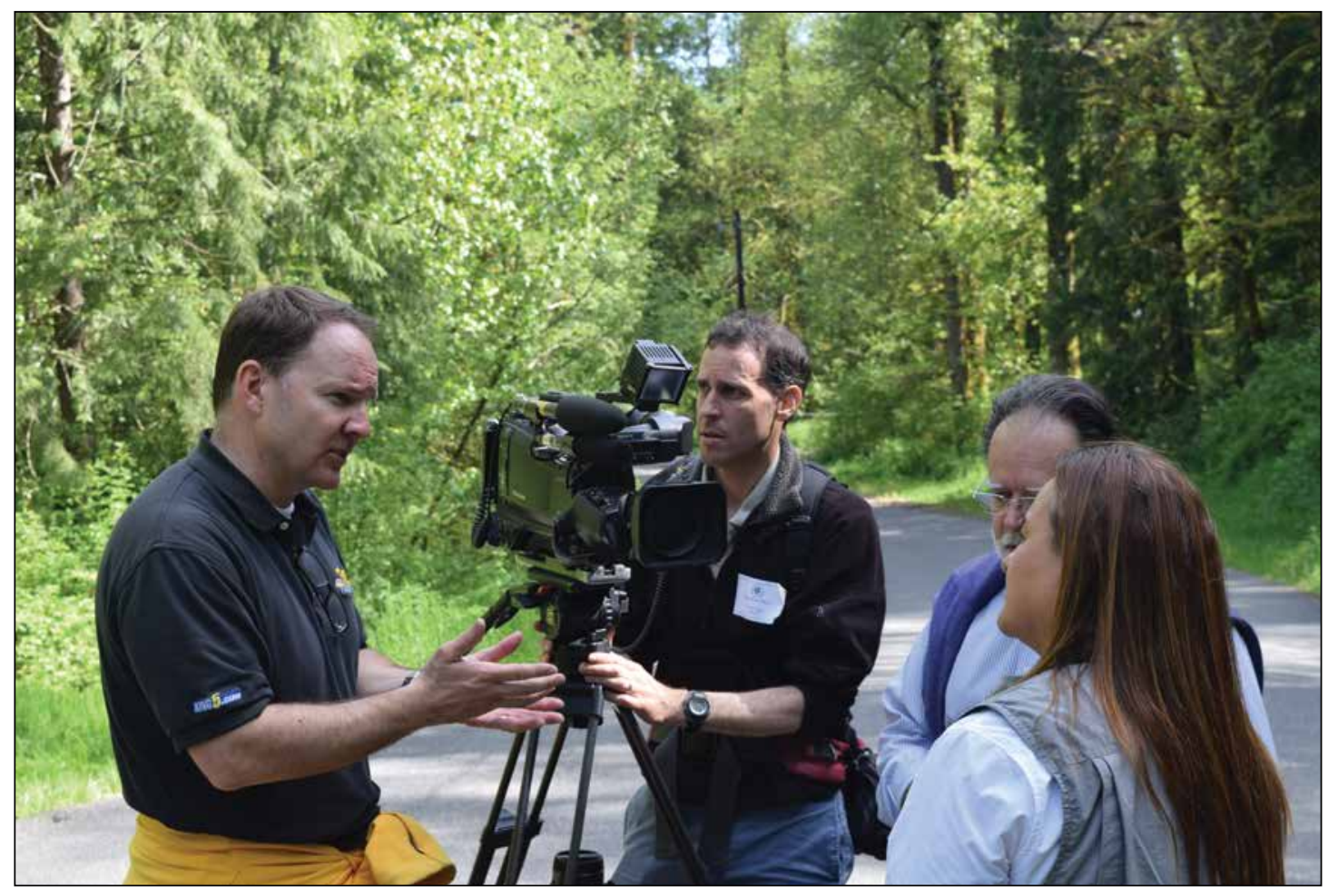

Members of the news media speak with Gloria Patricia Cortés of the Colombian Geological Survey (Servicio Geológico Colombiano) about her experiences with a lahar at Nevado del Ruiz. Cortés was part of a United States-Colombia binational exchange organized by the U.S. Geological Survey Cascades Volcano Observatory to increase local awareness of volcano hazards. USGS photograph by Jessica Ball, May 4, 2017. 
Table 1. Description of U.S. Geological Survey Cascades Volcano Observatory communication products.

[VAN, Volcano Activity Notice; VONA, Volcano Observatory Notice for Aviation; CVO, Cascades Volcano Observatory; USGS, U.S. Geological Survey; DOI, Department of the Interior; OCAP, Office of Communications and Publishing; PIO, public information officer]

\begin{tabular}{|c|c|c|c|}
\hline Product & Responsible staff & Duties or product & Dissemination/information outlet \\
\hline $\begin{array}{l}\text { Volcano Notification } \\
\text { Service }\end{array}$ & Rotating duty scientists & $\begin{array}{l}\text { Automatic updates about vol- } \\
\text { cano status and alerts, VANs } \\
\text { and VONAs (see References } \\
\text { section for more information). }\end{array}$ & $\begin{array}{l}\text { Email to registrants. Instructions for signing up for } \\
\text { the Volcano Notification Service are available at } \\
\text { https://volcanoes.usgs.gov/vns2. }\end{array}$ \\
\hline Website content & $\begin{array}{l}\text { Webmaster, social media } \\
\text { ambassadors }\end{array}$ & $\begin{array}{l}\text { Updated website content for } \\
\text { specific volcanoes and } \\
\text { monitoring techniques; new } \\
\text { pages as required. }\end{array}$ & CVO website, https://usgs.gov/cvo. \\
\hline $\begin{array}{l}\text { News current } \\
\text { events posts }\end{array}$ & $\begin{array}{l}\text { Webmaster, social media } \\
\text { ambassadors }\end{array}$ & $\begin{array}{l}\text { Short synopses of current events } \\
\text { and publications with links for } \\
\text { more information. }\end{array}$ & CVO website, https://usgs.gov/cvo. \\
\hline Social media & Social media ambassadors & $\begin{array}{l}\text { Posts about volcano status, } \\
\text { alerts, changing conditions, } \\
\text { and other volcano } \\
\text { information. }\end{array}$ & $\begin{array}{l}\text { USGS Volcanoes Facebook, USGS Volcanoes } \\
\text { Twitter, USGS Volcanoes Instagram and other } \\
\text { (USGS, DOI) social media accounts. }\end{array}$ \\
\hline $\begin{array}{l}\text { Teleconference } \\
\text { communication } \\
\text { about volcano- } \\
\text { related events with } \\
\text { agency partners } \\
\text { including PIOs }\end{array}$ & $\begin{array}{l}\text { Scientists, communications } \\
\text { staff }\end{array}$ & $\begin{array}{l}\text { When intense media interest is } \\
\text { expected, conduct interagency } \\
\text { teleconferences to inform } \\
\text { emergency staff and PIOs, } \\
\text { with updates as necessary. }\end{array}$ & $\begin{array}{l}\text { Teleconferences are sponsored and led in } \\
\text { Washington State by the Washington Emergency } \\
\text { Management Division (WEMD) and in } \\
\text { Oregon by the Oregon Office of Emergency } \\
\text { Management. }\end{array}$ \\
\hline
\end{tabular}

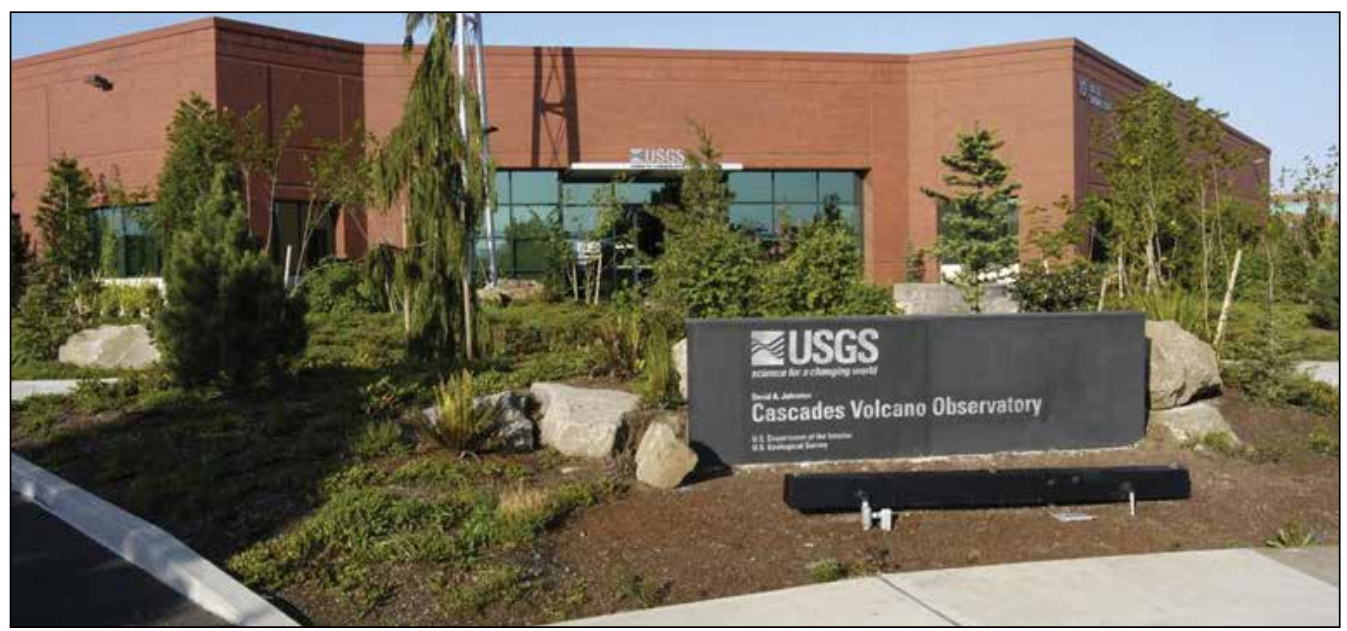

The U.S. Geological Survey Cascades Volcano Observatory (CVO) is located in Vancouver, Washington. CVO is responsible for identifying hazards and monitoring the behavior of active volcanoes in Washington, Oregon, and Idaho. USGS photograph by Carolyn Driedger, 2002. 


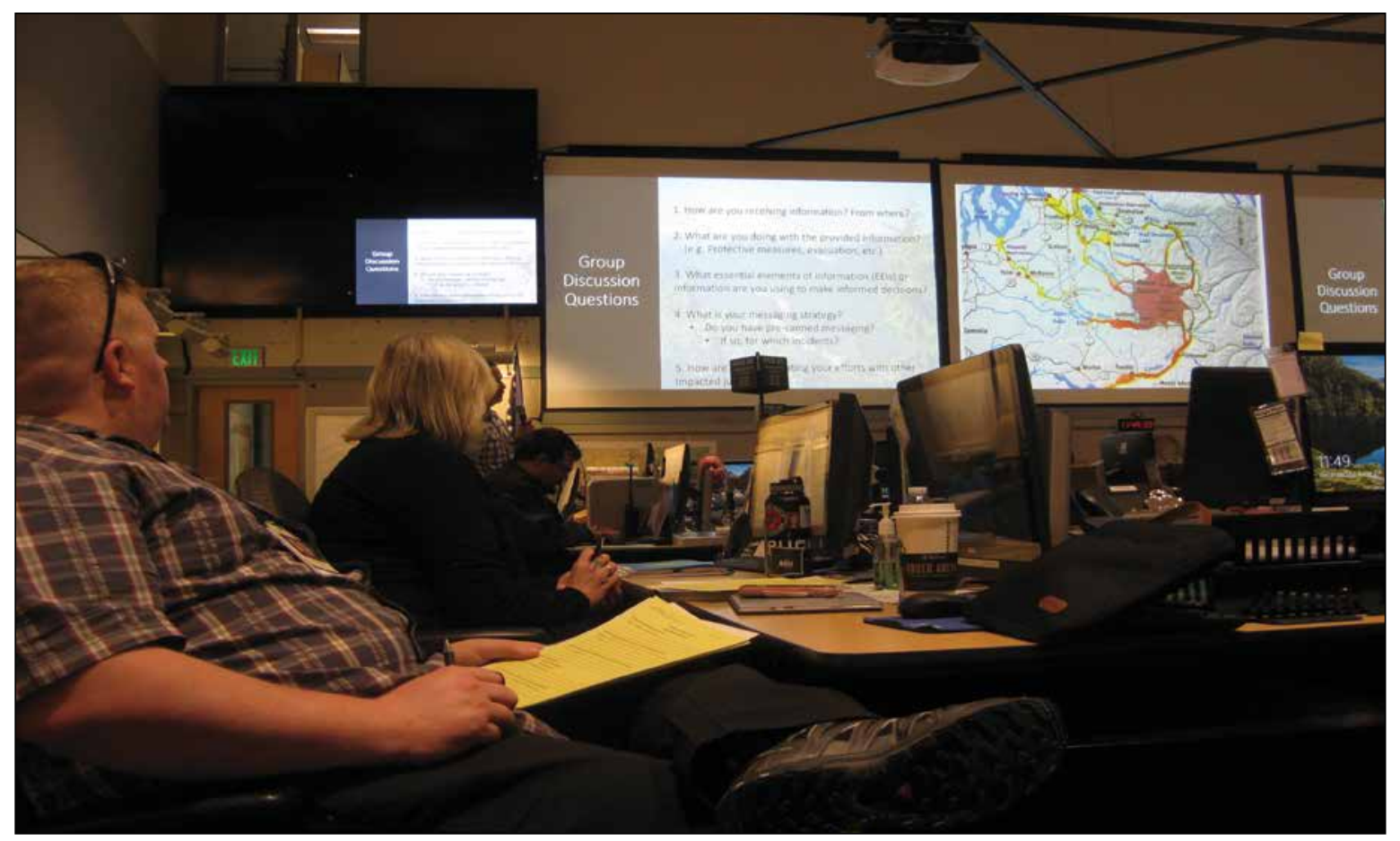

U.S. Geological Survey Cascades Volcano Observatory scientists and emergency management colleagues participate in a mock eruption response at the Washington Emergency Management Division. The exercise brought together representatives from State and local agencies to discuss how the agencies will work together to coordinate during an eruption. USGS photograph by Carolyn Driedger, June 27, 2018.

\section{Training for Communication During Crises}

Periodic trainings for the news media and CVO staff help develop skills necessary to foster better working relationships.

\section{Training for News Media}

CVO conducts occasional trainings about volcano science for reporters and journalists. Similar trainings for public information officers (PIOs) occur semiannually within PIO networks. A guidebook for the news media (Washington only) by Driedger and Scott (2010) contains key messaging so that the news media can familiarize themselves with terminology and volcano concepts. Informal visits to CVO by news media members can not only spur the creation of news stories, but also build trust with staff and knowledge about volcanorelated issues.

\section{Training for CVO Staff}

$\mathrm{CVO}$ and OCAP communications staff offer training in effectively interacting with the news media and working with reporters (appendixes 4, 6, 7). CVO staff with more in-depth interest can take locally offered PIO courses sponsored by the Federal Emergency Management Agency (FEMA) and State and local emergency management offices. See the Department of Homeland Security's National Incident Management System (NIMS) for in-depth descriptions of crisis communication tasks and courses. Hyer and Covello (2005) provide suggested guidelines for practical training.

CVO staff also build skills through regular interactions with information users and communicators. Most CVO partner agencies employ trained communications professionals, such as PIOs, educators, or park interpreters. CVO staff can enhance their professional skills by participating in associated meetings and trainings, requesting reviews of CVO information products, and building long-term working relationships that can expand the effectiveness of communication during crises. Two examples of multi-agency groups with welldeveloped communication programs are the Washington State Emergency Public Information Network (WEPIN, https:// www.facebook.com/washingtonepin/) and the Regional Disaster Preparedness Organization (RDPO, https://www. portlandoregon.gov/rdpo/58477) in Portland, Oregon. 


\section{Response to Inquiries at CVO}

\section{News Media Phone Inquiries}

Front desk personnel must be ready to direct news media inquiries to the appropriate $\mathrm{CVO}$ staff member or to other agencies. A list of CVO subject-matter experts and other information resources (partner agency contacts, maps, frequently asked questions [FAQs], and so on) can facilitate this. (See appendix 1 for a telephone list template.)

\section{News Media Emails, Webmaster Inquiries, and Social Media Comments}

CVO communications staff and social media ambassadors respond to inquiries from the news media and the public over email and social media. Emails, webmaster inquiries, and social media comments are typically monitored and distributed during normal working hours, which may be expanded during periods of intense media interest.

\section{Documentary Production Company Requests}

Documentary production companies often contact multiple USGS volcano observatories and OCAP simultaneously. One of the roles of communications staff is to aid coordination of responses.

\section{Documentary Request Form}

Encourage production companies to fill out the Documentary Request Form for USGS Involvement in Productions on the CVO Media Resources web page: https:// usgs.gov/cvo-media-resources (see also appendix 8). OCAP staff can assist with coordination of requests from producers.

Review of the form and conversations with filmmakers can promote $\mathrm{CVO}$ involvement in serious and worthwhile production efforts. Communications staff and the scientist-incharge will make the final decisions about CVO involvement and ensure that coordination among producers, scientists, and communications staff is effective.

Requests from production companies for images, graphics, and B-roll footage are routed to the CVO communications staff or the USGS Video Archive Manager in Denver, Colorado. (See appendix 8 for the Media Request Form and contact information.)

\section{Commercial Release Forms}

USGS employees cannot sign commercial copyright release forms when giving interviews or providing video material. Instead, USGS employees will fill out and send the applicable USGS-created form to the documentary producer.
OCAP maintains the forms on an internal web page and CVO communications staff or OCAP can answer questions. Copies of the fully signed document are kept for future reference.

\section{Image, Graphic, B-roll Footage, and Video Requests}

\section{Images and Generally Available Videos}

USGS work, including photographs and videos, are in the public domain. News media and members of the public can use images and graphics from CVO and the USGS Volcano Hazards Program (VHP) websites with credit that the graphic was provided "courtesy of the U.S. Geological Survey." Note that the USGS cannot give permission for others to use outside copyrighted material it alone has permission to use. No material will be provided to reporters unless it has been reviewed and approved (see USGS Fundamental Science Practices [USGS, 2019]).

Non-specific requests for photographs can be filled by directing the requestor to popular graphics, hazard maps, and online image galleries and video sites, such as

- CVO Multimedia website (https://usgs.gov/cvomultimedia). Upon request, it may be possible to find higher resolution versions of these images.

- USGS Denver Library Photographic Collection for historical images (https://library.usgs.gov/photo/); the USGS Multimedia Gallery (https://www.usgs.gov/ products/multimedia-gallery/overview); or USGS flickr account (https://www.flickr.com/photos/ usgeologicalsurvey/sets/).

- USGS Volcanoes Facebook, Twitter, and Instagram social media accounts.

- USGS YouTube Channel, https://www.youtube.com/ user/usgs.

\section{Graphics}

There is value in pre-crisis identification, development, and approval of foundational graphics that can be shared with the news media before and during a crisis. Identify your key messages, then determine how to address them visually. Graphics on the CVO website are in the public domain and may be used without restriction. Users are asked to indicate in the caption that the graphic was provided "courtesy of the U.S. Geological Survey." Graphics on the CVO website will be provided in the highest resolution possible.

\section{B-roll and Archival Footage}

Send detailed inquires to the USGS Video Archive Manager (in Denver, Colorado) using the link to request footage at https://www.usgs.gov/news/im-a-reporter. 


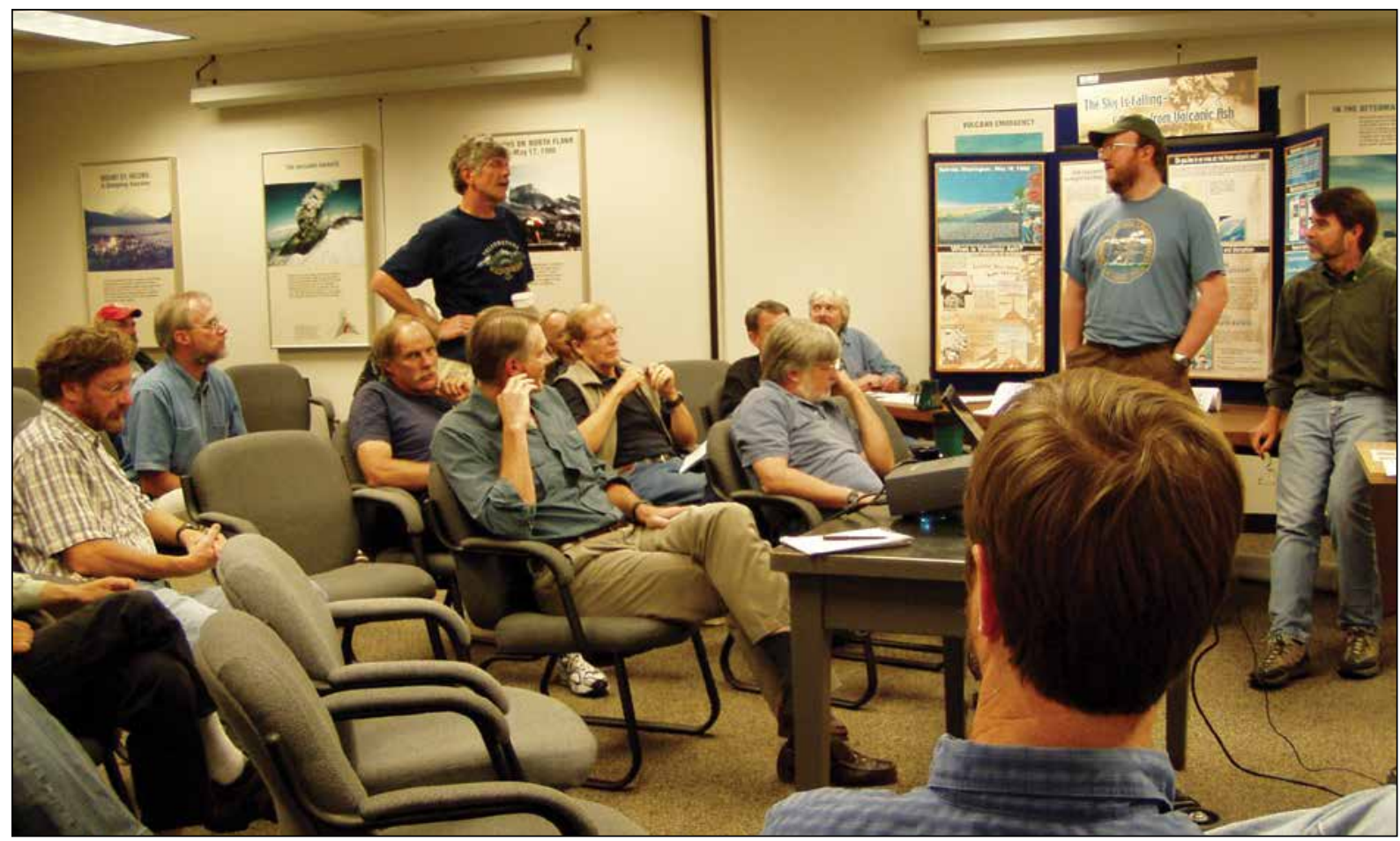

During volcanic activity in 2004, scientists at the U.S. Geological Survey Cascades Volcano Observatory discuss potential eruption outcomes. They state their consensus in a series of talking points that guide their messaging when speaking with news media. USGS photograph by Carolyn Driedger, October 1, 2004.

\section{Providing Large-File Images and Graphics to the Public}

CVO provides images and video to the public through its website and social media accounts. The preferred method is for users to download images or videos directly from those public sites. If that is not possible, files can be transferred by email, although there is currently a $25 \mathrm{MB}$ limit on attachments. Larger files can be transferred through a USGS FTP site.

\section{Geospatial Data and Products}

CVO geospatial scientists work with USGS colleagues and partner agencies, as appropriate, to acquire the base maps,
"Know beforehand what you want to say and how you are going to say it. That way, reporters will use the quotes you want them to use." - Hays and Grossman, 2006 visualizations of modeled results and volcano hazard maps; data about changing conditions such as lava flow advance and lava dome growth; and web maps and web mapping services for rapid release of map products to support risk assessment. Geospatial scientists coordinate with colleagues, outreach staff, social media ambassadors, and website personnel to ensure accuracy of geospatial products and messages.

\section{CVO News Media Helicopter Policy}

Current CVO policy states that staff cannot fly with the media, even in Department of the Interior (DOI) Office of Aviation Services (OAS)-carded helicopters. For CVO interviews, alternative measures include offering on-ground and at-CVO interviews and use of digital elevation models, imagery, and field data necessary to develop required geospatial products. These products may include scenario maps derived from the outputs of volcano hazard models such as LAHARZ, Ash3D, and D-Claw;

"If no new information becomes available in a timely manner, let the audience know that the risk is still being studied and that they haven't been forgotten...."

—Lundgren and McMakin, 2013 



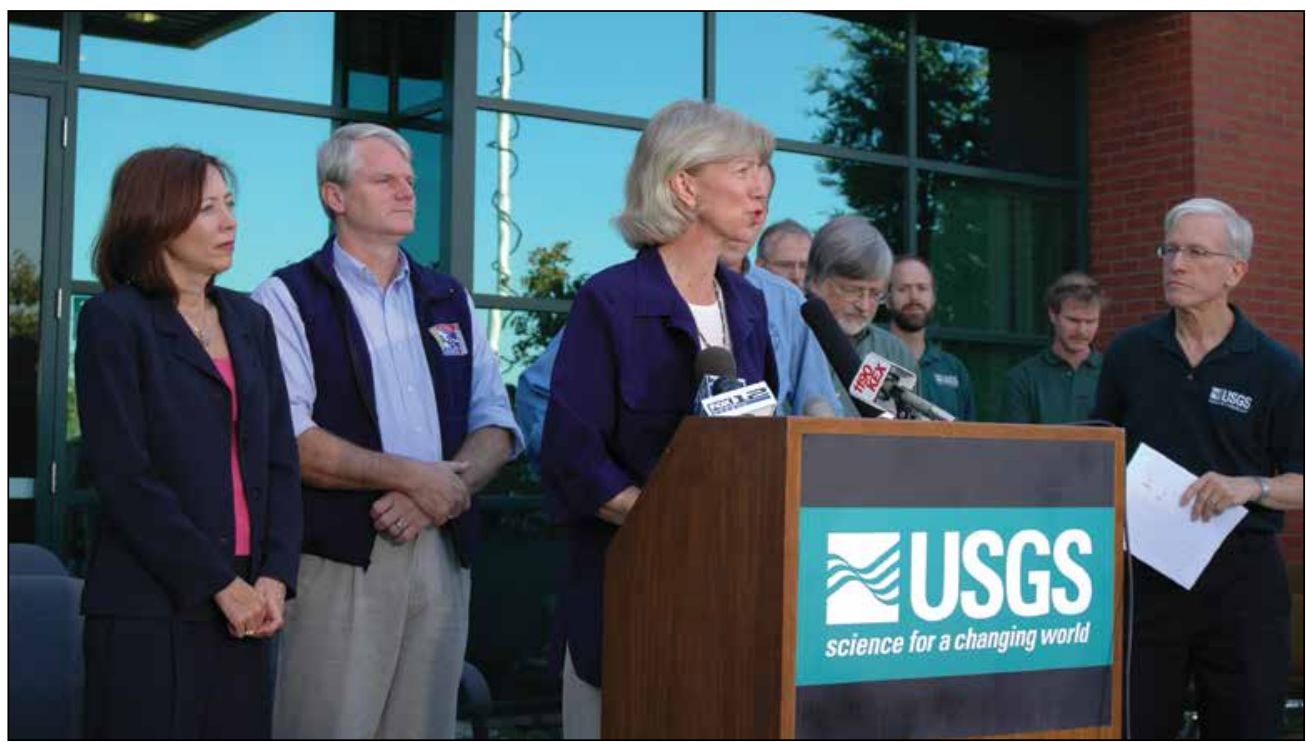

Former Secretary of the Interior Gale Norton (at lectern), Senator Maria Cantwell (left),

Washington State Representative Brian Baird (second from left), and U.S. Geological Survey

Cascades Volcano Observatory (CVO) scientists (far right) address members of the news media

outside CVO in Vancouver, Washington. USGS photograph by Elliot Endo, October 2, 2004.

\section{Response to Intense Media Interest}

This section describes necessary actions for periods of rapid acceleration in media interest. Some of the actions listed as necessary at more advanced levels may be additive to actions listed at lower levels.

\section{Developing Products and Messages}

The scientist-in-charge should advise scientists to send all news media requests directly to communications staff for coordination. This will allow scientists to concentrate on their scientific endeavors. This temporary severing of ties can be difficult, but it is necessary, especially for scientists who are well acquainted with news media members.

Initially, intense news and social media interest will likely trigger the need for coordination and a teleconference with local emergency and land management officials. In Washington, the teleconference will be with the Washington Emergency Management Division (WEMD), and there may be additional teleconferences with agency PIOs. In Oregon, initial communication will be coordinated through the Oregon Office of Emergency Management (OEM). This process often happens within the hour prior to CVO issuing changes in the Volcano Alert Level.

Guidance on what to do during the first few moments of any reported volcanic activity are provided in the Volcano Rapid Reference Guide (appendix 11). Local volcano coordination plans also provide general guidance about media coordination and can be found as follows: Washington Volcano Coordination plans, http://mil.wa.gov/plans; and Oregon plans, https://www.oregon.gov/OEM/Documents/ Mount_Hood_Volcano_Coordination_Plan.pdf.
Immediate actions may include developing an Information Statement and talking points and compiling a list of PIO contacts. Assign a single email address to which the news media can send their questions. Additionally, communications staff may be called upon to aid the scientist-in-charge and scientists in developing products for the USGS Volcano Notification Service (VNS) (https://usgs.gov/volcanonotifications), such as Information Statements, Volcano Activity Notices (VANs), or Volcano Observatory Notices for Aviation (VONAs). A news media release might provide additional content, or a news media advisory might provide a schedule of CVO scientist availability and (or) press conferences.

The VSC internal protocols outline instruction for conveying information internally concurrent with the news media response. When the news media contacts multiple observatories with the same requests, observatories will need to coordinate their response. Additional staff may be added to CVO to aid in coordinating and implementing a media response, available either in person or by phone or email from other USGS offices.

\section{Preparation of Talking Points; Rapid Coordination of Message Development}

Communications staff at $\mathrm{CVO}$ will maintain talking points about the volcanic activity. Written materials and graphics should explain "What is happening," "What is the impact," and "What are we doing about it." Expect that after about 48 hours, the news media and public will focus more intently on the event, requesting more specific information about cause, what scientists have learned, safety, and how long the event will last. The news media and public will have 
questions about how events impact their family and mitigation measures. Visual aids such as maps, graphics, images, or video are increasingly critical for news outlets and should be assembled for dissemination via the internet.

Talking points are for internal use by CVO staff and partners and are not distributed to the news media or public. (See appendix 4 for CVO talking point guidelines.) Management, scientists, and all communications specialists (including social media ambassadors and website personnel) must be involved and informed about the situation and actions to be taken.

\section{Parallel Communication}

Users with interests in the broader scope of communication should keep in mind that in addition to interactions with the news media, parallel and multifaceted lines of communication are maintained with USGS external partners and with management of the USGS and DOI. These communiciatons lines exist for the purpose of maintaining situational awareness and for fulfilling information needs of partners who have missions of risk reduction.

\section{External Partners}

The scientist-in-charge will keep key agencies informed by providing periodic situation reports and updated talking points. An informal JIS might be established so that each agency can deliver messages germane to its mission and focus on conveying information it is qualified to share. External contacts may include the Pacific Northwest Seismic Network; specific U.S. Forest Service or National Park Service personnel; Federal, State, or county emergency managers; and emergency responders responsible for the area of interest. Contact lists are updated periodically as part of a communication plan or volcano coordination plan.

\section{Internal Management}

In a separate line of communication, VSC management uses the same news media release material to create situational reports ("Sit Reps") that are regularly distributed to USGS and Department of the Interior (DOI) leadership. All interactions with the congressional staff members and elected officials are conducted by the Volcano Science Center Director and staff at OCAP.

\section{Delivering Products and Messages}

Shared digital platforms and large group engagements can be the most effective ways to address the news media. This includes holding press conferences in large facilities (often at secondary sites), conducting video and teleconferences with the media, and arranging special media days at the volcano.

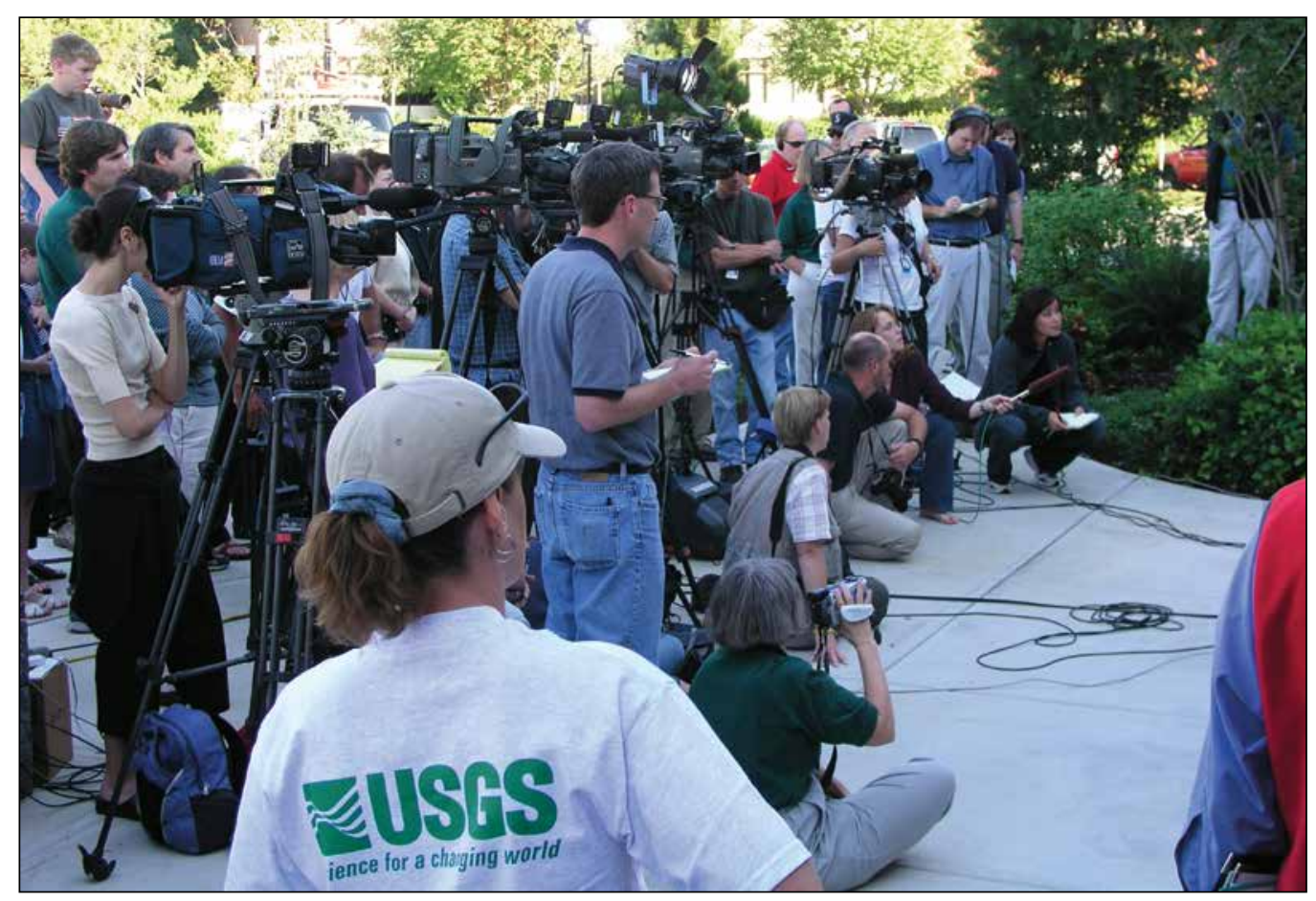

Members of the news media gather outside the U.S. Geological Survey Cascades Volcano Observatory during a briefing held in Vancouver, Washington. USGS photograph by Elliot Endo, October 2, 2004. 
"Interviews conducted during a crisis aren't easy. Something bad has happened and nobody is happy about it, yet you have to face the press and answer questions. What you say is important, but so is how you say it. Your face should reflect the gravity of the situation. If you're tired because of the strain caused by the crisis, it's okay to show that. At the same time, you want to appear strong and confident so you inspire faith in your organization as well as your words."-Beckwith, 2006

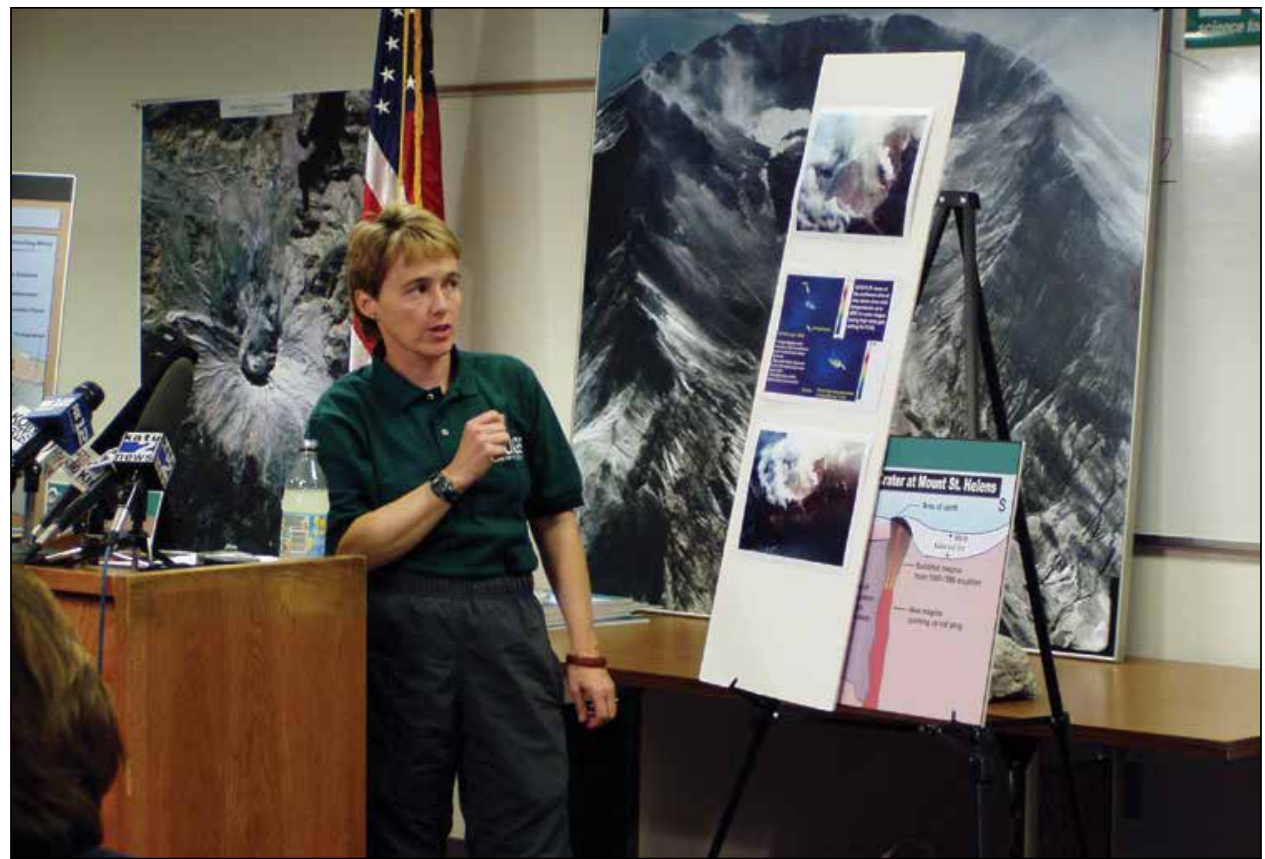

U.S. Geological Survey scientist Tina Neal addresses the news media using photographs and graphics to describe events and potential outcomes. USGS photograph by Carolyn Driedger, October 22, 2004.

\section{News Media Briefings (Press Conferences)}

News media briefings or press conferences generally take place at CVO. While CVO staff can organize media briefings as needed, OCAP takes responsibility for organizing larger, more formal assemblies and will have the most current procedures. These briefings can be in person, video or teleconferences, or a combination of appropriate technologies.

Plan for an audio bridge or other technology to accommodate news media outside the local area (OCAP can assist in arranging this). Other locations may be found for media briefings if unrest escalates and larger facilities outside of CVO are needed.

After assembling an agenda for the news briefing, post it to the CVO Media Resources website and distribute it both in paper and electronic form. Along with agenda items, include names of speakers, statistics pertinent to the event, major points, a list of online resources, and the time of the next news briefing (and what you intend to know at that time). Also provide maps and graphics in hard copy and electronic (PDF) formats. Be aware of the USGS Fundamental Science Practices (USGS, 2019), and only distribute images, maps, or posters that have been reviewed and approved to the news media. On-the-spot documents that have not been reviewed can be created for briefings, but they should not be further disseminated.

The entire briefing (USGS and partner statements) should be no more than one-half hour in length, not including times for individual interviews. If there are multiple speakers, each speaker should make a very short statement of what they know or what has changed and open the briefing for questions from reporters.

For news media briefings at CVO, the USGS logo should be on the lectern and USGS speakers should wear the USGS logo on their apparel. Any backdrop images behind the speakers should be appropriate for the audience and the activity. Speakers should have easy access to monitoring instruments, rock and ash samples or other tangible items, images, maps, graphics, or video as needed.
"There is nothing more powerful than the first-person narrative-the voice that can speak to a crowd and say, "This is what I know; this is what I have experienced; this is how I feel."-Olson, 2009 


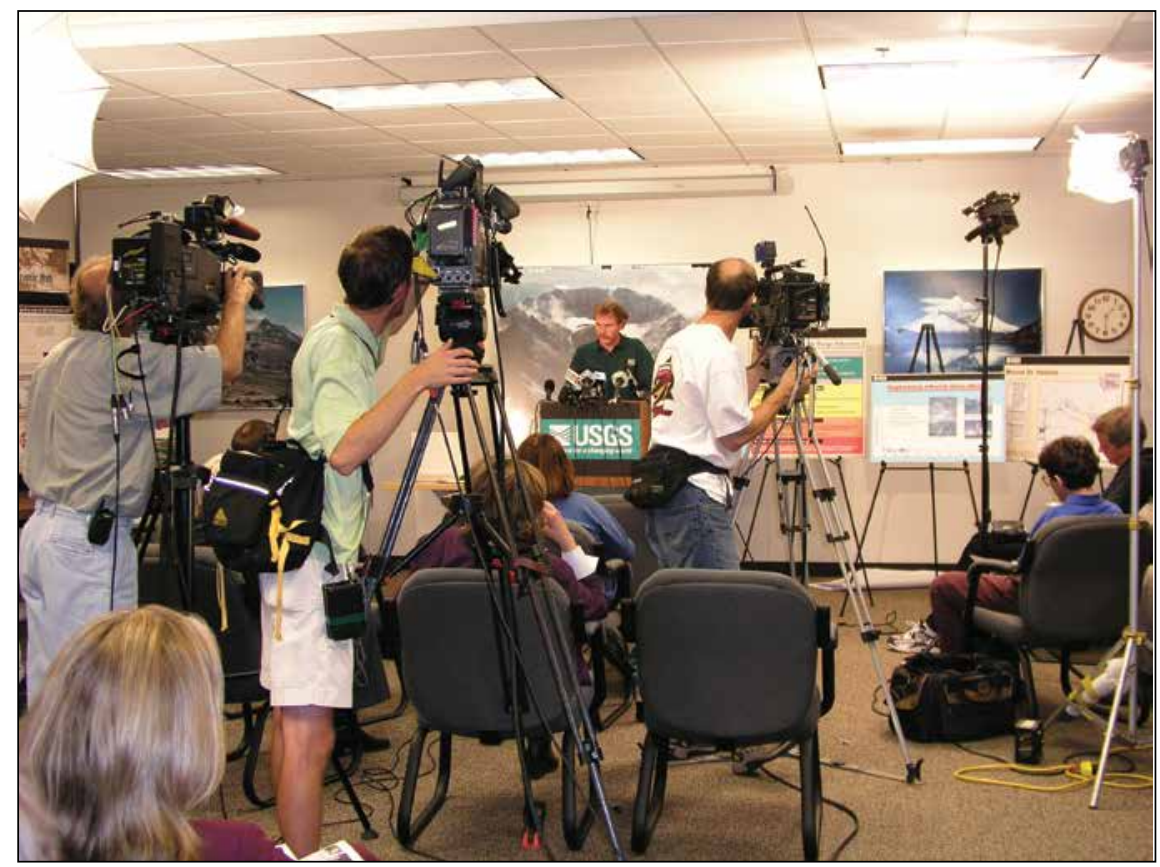

Staff conduct a press briefing at the U.S. Geological Survey Cascades Volcano Observatory. USGS photograph by Lyn Topinka, October 1, 2004.

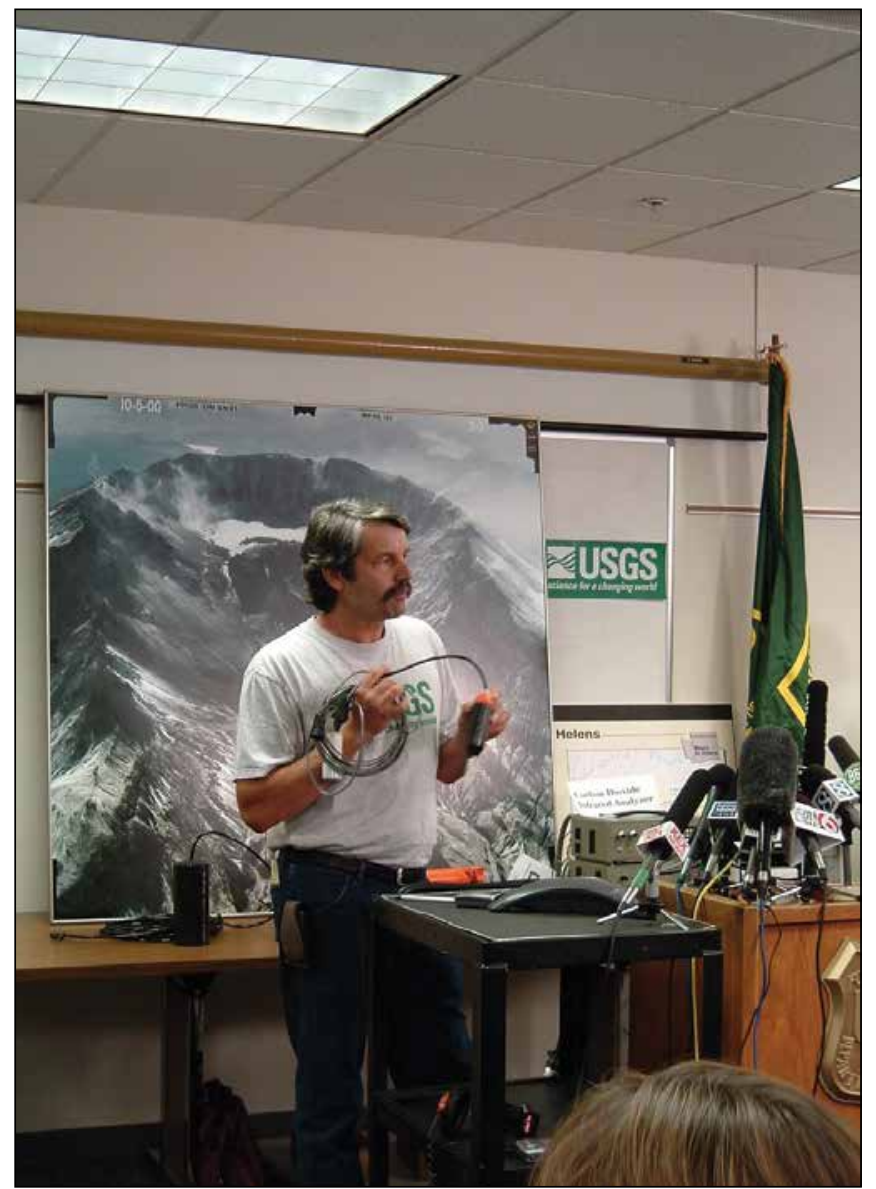

U.S. Geological Survey scientist Rick LaHusen holds a seismometer as he talks about earthquakes and monitoring networks. USGS photograph by John Clemens, October 6, 2004.

\section{Media Days and Group Interviews}

During intense media interest, scientists have a dual role of monitoring volcanic activity and communicating information to the public. To facilitate the transfer of information, requests from film or television documentary production companies may be consolidated by holding designated media days and group interviews in the field. In cases where access is limited, the selection of a single media pool group that consists of a television reporter and a television camera operator, a radio reporter, and a print reporter and a print photographer is efficient. The pooled material such as generic B-roll footage and images are then made available on a "feed" to everyone at the same time. Organizations like news networks, the AP, and larger radio conglomerates are often familiar with this practice.

\section{Individual Interviews}

Individual interviews require a quiet area with sufficient space to accommodate cameras and production staff. Most often, an indoor location such as the library, conference room, or lobby is best. Outdoor locations, such as the front patio are also available, weather permitting.

Examine the location in advance to determine that sensitive information has been removed and it is ready to receive guests. Ensure that a USGS logo is visible. Consider suitable backdrops such as background graphics and images. Request computer staff to aid set up of a mobile monitor with displays of images, video, data, or other electronic or computer-generated information. Post a sign on the door or nearby indicating an interview is in progress to minimize noise and disruptions. 


\section{Recommendations for News Media Briefings}

During the 2004 reawakening of Mount St. Helens, Washington, news media representatives split their time between the JIC at the Gifford Pinchot National Forest Superintendent's Office and a viewpoint at the Mount St. Helens National Volcanic Monument. The news media preferred to be at the viewpoint so it was important to have USGS subjectmatter experts available and to provide a daily selection of stories and interviews at the volcano. The consensus, however, was that briefings went better indoors than outdoors.

Scientific staff who provide interviews should consider the following recommendations:

- Portray a broad perspective on the situation in nontechnical terms.

- Have a good grasp of the situation, including up-to-date information, the latest talking points, and overarching messaging about Cascade Range volcanoes and the VHP.

- Know your limits-science. Know where to refer non-science questions or questions that you cannot authoritatively answer.

- Use a narrative style and chronological order to talk about natural events and their and impacts, especially when explaining cause and effect. This can help you to link science with stories of people, including individuals at risk.

- Take some tangible objects that can help you to explain the science (rocks, small posters, and equipment). Save larger items for indoor briefings.

- Review best practices for good interviews in appendix 6 .

- If you are in the field, keep the current information pathways open by bringing a satellite phone or radio and (or) using a telephone to make contact with $\mathrm{CVO}$ before moving into a zone of no coverage; make arrangements with staff at land-management agencies to receive updates via email, phone, and possibly texting and messaging.

- Have plenty of USGS logo clothing on hand - shirts, jackets, hats, and especially any appropriate safety gear - to wear during interviews and briefings.

- Never display unsafe behavior or make inappropriate remarks. Everything is always "on the record."

- Keep in mind that citizens may be filming or broadcasting the event on social media. As above, everything is always "on the record."

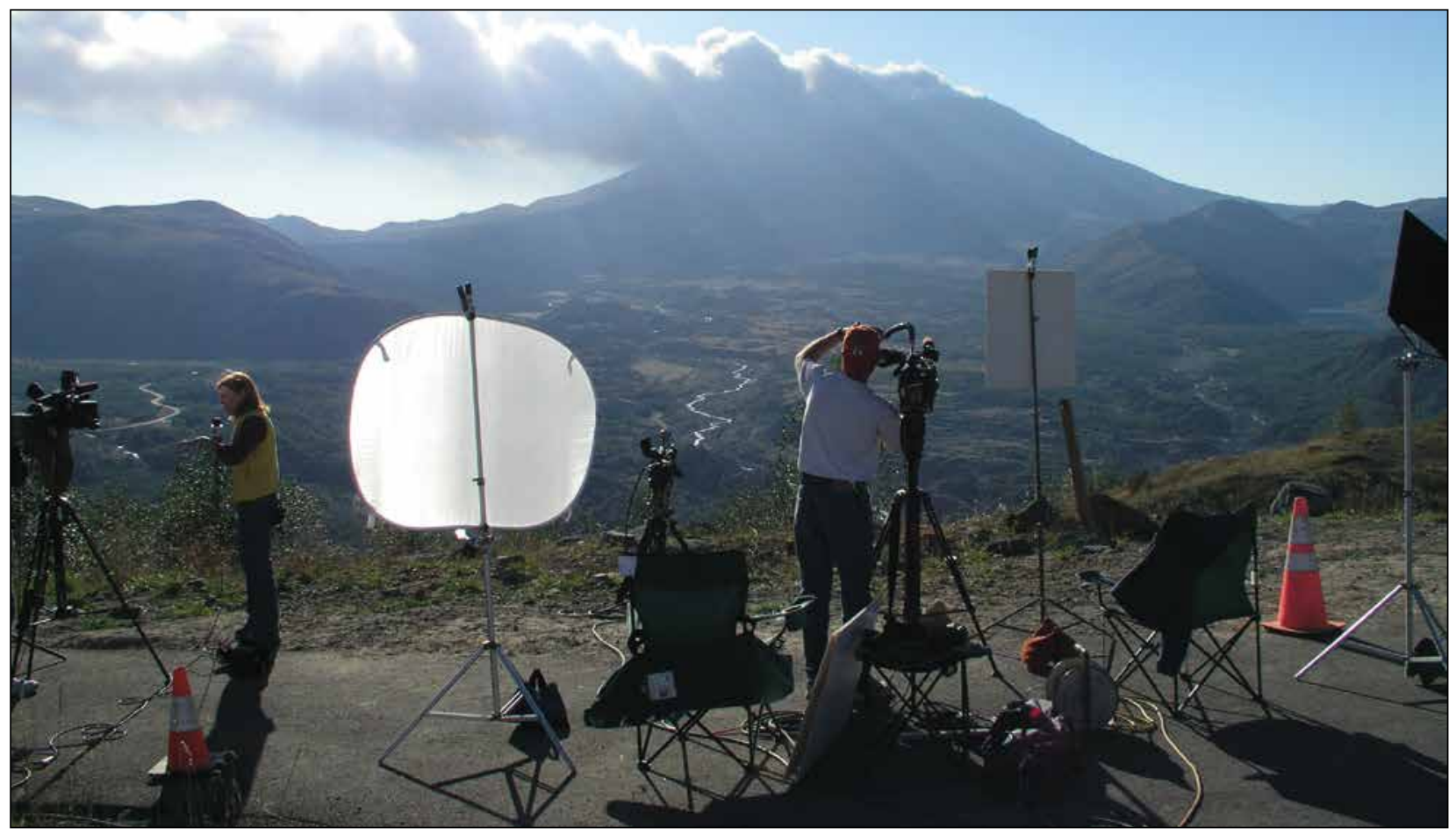

Members of the news media broadcast from the Castle Lake viewpoint, west of Mount St. Helens, Washington. USGS photograph by Jon Major, October 5, 2004. 


\section{Participation at Public Meetings}

CVO may participate in public meetings organized by partner agencies. Discussions prior to the public meeting will confirm the issues to be discussed, available subject-matter experts and staffing for the meeting. Information about the time, location, and issues to be discussed will be posted on the CVO website and USGS social media accounts.

\section{Communication Duties During Intense Media Interest (no formal JIC)}

During intense media interest with no formal JIC, normal outreach tasks generally are put aside, and staff focus on communication. The following lists provide an overview of the expected tasks and responsibilities.

\section{Scientist-in-Charge}

During intense media interest, the scientist-in-charge does the following:

- Appoints a communications coordinator to oversee media communication during the event.

- Maintains overall responsibility for development of management briefing documents for USGS internal communication, including principal points, images, graphics, and chronology.

- Assigns outreach staff to develop plain language text in Activity Updates and related products.

- Communicates frequently with the communications coordinator regarding progress, concerns, and needs.

- Keeps VSC director informed, so the director can keep the USGS VHP and Natural Hazards Mission Area informed.

- Authorizes key messages to be used in interviews and products.

- Aids in obtaining additional communications staff.

- Approves any new graphics, maps, and other products for distribution to the news media.

\section{Communications Coordinator}

During intense media interest, the communications coordinator, who is appointed by the scientist-in-charge, ensures that the roles below are filled and that there is proper communication between involved parties. The communications coordinator does the following:

- Communicates regularly with the scientist-in-charge to ensure that media response needs can be addressed effectively with current staffing.
- Champions clear and consistent messaging in all communications

- Participates in developing background materials and status reports.

- Aids CVO management in developing internal management briefing documents; works with VHP and VSC management and OCAP to coordinate CVO external portions of media responses; and works with OCAP to keep the USGS director, DOI officials, and Congress apprised of the situation as it evolves.

- Maintains contact with inter-agency PIOs regarding the need for a JIC or JIS.

- Coordinates interviews and preparation of subjectmatter experts for the interviews.

- Ensures that news media email requests and phone calls are addressed effectively, ascertains needs for aid from OCAP and other VSC observatories, and speaks with OCAP about mechanisms that can improve efficiency.

- Tracks news stories to assess accuracy.

- Ensures maintenance of inquiries recorded on an internal-use shared drive folder; during large events, DOI will want a daily report.

- Creates a daily checklist for guests who are helping with media management.

- Oversees production of B-roll footage and images.

- As time allows, oversees creation of special educational products.

\section{OCAP}

During intense media interest, OCAP does the following:

- Aids in assignment of a special email address for the news media to send their interview request and creates a shared access document to log and track fulfillment of requests.

- Aids in facilitating news briefings, whether they be in person or virtual.

- Facilitates development, approval, and distribution of news releases and media advisories; helps coordinate public inquiries; and manages all congressional affairs.

- Facilitates general USGS postings of high-interest information on USGS websites and social media accounts in coordination with VHP social media ambassadors and website personnel.

- Provides archived B-roll footage to the news media and aids in developing new material as requested. 


\section{VHP Social Media Ambassadors and Website Personnel}

During intense media interest, VHP social media ambassadors and website personnel do the following:

- Work with the communications coordinator and scientists to develop talking points.

- Work with other communications and science staff to promote consistent word usage and messaging in interviews and products.

- Work with scientists and the communications coordinator to ensure that VNS updates and website and social media messages are in alignment.

- Coordinate as needed with OCAP so news is crossposted on USGS webpages.

- Coordinate with social media staff at external partner agencies.

- Track and address incoming social media communication; monitor the general public's perceptions and concerns; and make timely interjections, corrections, and comments.

- Answer social media comments, incoming email, and web requests from the public or pass them to other staff.

- Provide new images, video, and graphics for the CVO website and social media accounts or to image or video databases.

- Inform other outreach staff about FAQs and needs for communication updates.

- Develop a template to convey up-to-date images, graphics, and text for situational awareness (this may take the form of a new web page [see appendix 9]).

- Update material on the CVO and VHP websites (News posts, news resources, new web pages) as required.

- Maintain contacts with inter-agency PIOs regarding potential participation in a JIC or JIS.

\section{Graphics Illustrators}

Charts and illustrations are often needed for news briefings, websites, and social media posts. During intense media interest, graphics illustrators do the following:

- Develop and update visual information products for distribution to news media, social media, the CVO website, public meetings, and agency partners.

- Prepare exhibits or posters for daily press briefings or news conferences, including arranging for mounting and lamination.

- Coordinate with scientists, the communications coordinator, social media ambassadors, geospatial scientists, and website personnel to ensure accuracy of images, maps, and messages.
- Keep the scientist-in-charge informed of resources required for creation of quality products and obtain approval for new and significantly updated graphics and map products.

- Coordinate with USGS colleagues and partner agencies, as appropriate, to acquire base maps, imagery, and digital elevation data necessary to develop required products.

\section{Geospatial Scientists}

During intense media interest, geospatial scientists do the following:

- Acquire base maps, digital elevation models, imagery, and field data necessary to develop required geospatial products. These products may include scenario maps derived from the outputs of volcano hazards models such as LAHARZ, Ash3D, and D-Claw; visualizations of modeled results and volcano hazard maps; data regarding changing conditions such as lava flow advance and lava dome growth; and web maps and web mapping services for rapid release of map products to support risk assessment.

- Coordinate with colleagues, outreach staff, social media ambassadors, and website personnel to ensure accuracy of geospatial products and messages.

- Inform the scientist-in-charge of the resources required to create and release quality geospatial products that meet internal USGS, external partner, and news media needs.

\section{Scientists}

During intense media interest, scientists do the following:

- Aid the scientist-in-charge and other scientists in developing products for volcanic activity updates, which will be available to the news media.

- Participate in development and review of talking points.

- Coordinate with communications staff to promote consistent word usage and messaging in interviews and products.

- Develop talking points that express a broad view of volcanic activity, put current activity in perspective, and show implications and relevance to people.

- Coordinate with partner agencies and co-authors to maintain consistent word usage and messaging.

- Provide interviews at CVO, in the field, at a JIC, or at a public meeting.

- Create photographs and video documenting fieldwork (including metadata) and upload to a centralized database.

- Route all incoming media requests to the communications coordinator. 
"The JIC can be viewed as a central hub for communication, a "one-stop shopping" facility where representatives from cooperating agencies can address inquiries with a single voice. The use of a JIC reduces confusion, inaccuracies, and duplication of efforts and can help address rumor control."-Diedger and others, 2008

99

\section{Multi-Agency Response with an Incident Command Joint Information Center or System}

A Joint Information Center (JIC) is a multi-agency central coordination point for dissemination of timely and accurate incident information to the public and news media, external affairs activities, and news media access. A Joint Information System (JIS) is a multi-agency central virtual system with a similar purpose. Both are used during times when an Incident Command has been established and is run by the larger command structure, sometimes known as a MAC (multiagency coordination) Group Command or joint operations center. Communication requests may ramp up with development of a JIS followed by the eventual opening of a JIC and then later shrink back to a JIS.

The JIC is a co-located site for local, State, and Federal information staff to attain a coordinated incident information response. A JIC can be assembled when communication needs exceed the capacity of individual agencies. It is scalable and flexible to adapt to the size and scope of the incident.

The JIC provides interagency coordination and integration, development and delivery of coordinated messages, support for decision makers, and flexibility to meet needs based on changing circumstances. Although the public can receive information from any source, a JIC allows the various organizations with responsibility during incidents to come together to ensure that information disseminated to the public is accurate, understandable, timely, and consistent. Distribution and dissemination of information approved by a MAC Group Command is through JIC communication, including news media releases, interviews, news media briefings, social media posts, and website products. A general call center and other office resources are shared, and technical representatives from specific agencies address inquiries germane to their agency's focus.

Outside the JIC, each organization maintains its own authority and policies but contributes to an overall unified message presented to the public in the JIC. Individual agencies will speak to their specific statutory responsibilities with prior coordination of information releases.
"A major lesson learned in 2004 was the speed with which public and media response can outpace the actual progression of eruptive events."-Frenzen and others, 2008 


\section{Communication Duties In Support of the JIC or JIS}

The following lists provide an overview of some of the expected tasks and responsibilities when a JIC or JIS is in place. (See resources offered by the Department of Homeland Security concerning the National Incident Management System [NIMS] and crisis communication during a JIC or JIS.)

\section{Scientist-in-Charge}

When there is a JIC or JIS, the scientist-in-charge does the following:

- Appoints a communications coordinator who can serve as the principal communications liaison between the USGS and the JIC.

- Maintains overall responsibility for developing Management Briefing documents for USGS internal communication, including principal points, images, graphics, and chronology.

- Assigns outreach staff to develop plain language text in USGS Activity Updates and related products.

- Maintains close coordination with the communications coordinator regarding USGS alert-level changes and messaging concerning ongoing activity.

- Communicates frequently with the USGS communications staff liaison within the JIC regarding progress, concerns, and needs.

- Authorizes key USGS messages to be used in interviews and products.

- Approves any new USGS graphics, maps, and other products for distribution to the news media.

- Aids in obtaining additional USGS communications staff.

\section{Communications Coordinator}

When there is a JIC or JIS, the communications coordinator, serving at the wishes of the scientist-in-charge, performs the role of consultant and liaison at the JIC or JIS, ensures that the roles below are filled, and ensures that there is proper communication between involved parties. The communications coordinator does the following:

- Communicates regularly with the scientist-in-charge about concerns and needs as seen at the JIC or JIS.

- Participates in developing USGS talking points and incorporating them into JIC or JIS products. Champions clear and consistent communication.

- Works with JIC staff, social media ambassadors, and scientists for alignment of word usage and descriptions of events used in interviews, on the CVO website and social media, and in personal communication.
- Prepares USGS science staff for participation in JIC or JIS media interviews.

- Maintains a list of USGS scientists prepared to speak in interviews and news briefings.

- Tracks JIC or JIS messages within news stories and takes action to correct inaccuracies.

- Oversees production of USGS B-roll footage and images.

- As time allows, oversees USGS creation of special educational products.

\section{OCAP}

When there is a JIC or JIS, OCAP does the following:

- Facilitates the information feed to congressional staff, senior levels of the USGS, and DOI.

- Facilitates general USGS postings of high-interest information on USGS websites and social media.

- Facilitates development, approval, and distribution of news releases and media advisories at the JIC or JIS.

- Aids CVO communications staff in answering inquiries within the JIC or JIS structure.

- Provides archived USGS B-roll footage to the news media and aids in developing new material as requested.

- When requested by the scientist-in-charge, aids CVO communications staff as needed, including back-filling CVO communications jobs.

\section{VHP Social Media Ambassadors and Website Personnel}

When there is a JIC or JIS, social media ambassadors and website personnel do the following:

- Maintain contact with inter-agency PIOs as needed for a JIC or JIS.

- Work with JIC or JIS staff and other partner agencies to ensure consistency and coordination of messaging on social media accounts and the $\mathrm{CVO}$ website.

- Work with the communications coordinator and USGS scientists to develop talking points.

- Coordinate as needed with OCAP so news is crossposted on USGS social media sites.

- Track and address incoming USGS social media communication; monitor the general public's perceptions and concerns; and make timely interjections, corrections, and comments.

- Answer USGS social media comments, incoming email, and web requests from the public or pass them to other staff. 
- Provide new images, video, and graphics for the CVO website and social media accounts or to image or video databases.

- Inform other outreach staff about FAQs and needs for communication updates.

- Develop a template to convey up-to-date images, graphics, and text for situational awareness (this may take the form of a new event web page [see appendix 9]).

- Update material at the CVO and VHP websites (News posts, news resources, creation of new web pages) as required.

\section{Graphics Illustrators}

There can be an almost constant need for charts and illustrations for news briefings, websites, and social media posts during a JIC or JIS. When there is a JIC or JIS, graphics illustrators do the following:

- Develop and update visual information products for the JIC or JIS for distribution to the news media, social media, the CVO website, public meetings, and agency partners.

- Coordinate with USGS scientists, the communications coordinator, social media ambassadors, geospatial scientists, and website personnel to ensure accuracy of images, maps, and messages.

- Keep the scientist-in-charge informed of resources required for creation of quality products and obtain approval for new and significantly updated graphics and map products.

- Coordinate with USGS colleagues and partner agencies, as appropriate, to acquire base maps, imagery, and digital elevation data necessary to develop required products.

\section{Geospatial Scientists}

When there is a JIC or JIS, geospatial scientists do the following:

- Acquire base maps, digital elevation models, imagery, and field data necessary to develop required geospatial products. These products may include scenario maps derived from the outputs of volcano hazards models such as LAHARZ, Ash3D, D-Claw; visualizations of modeled results and volcano hazard maps; data regarding changing conditions such as lava flow advance and lava dome growth; and web maps and web mapping services for rapid release of map products to support risk assessment.

- Coordinate with colleagues, outreach staff, social media ambassadors, and website personnel to ensure accuracy of geospatial products and messages.

- Inform the scientist-in-charge of the resources required to create and release quality geospatial products that meet internal USGS, external partner, and news media needs.

\section{Scientists}

When there is a JIC or JIS, scientists do the following:

- Aid the scientist-in-charge and other scientists in developing volcanic activity updates, which will be available to the news media.

- Coordinate with partner agencies to deliver geospatial products germane to the larger response effort.

- Participate in development and review of USGS talking points.

- Coordinate with communication staff to ensure consistent messaging in interviews and products.

- Provide interviews for the JIC or JIS. 


\section{Appendixes 1-11}

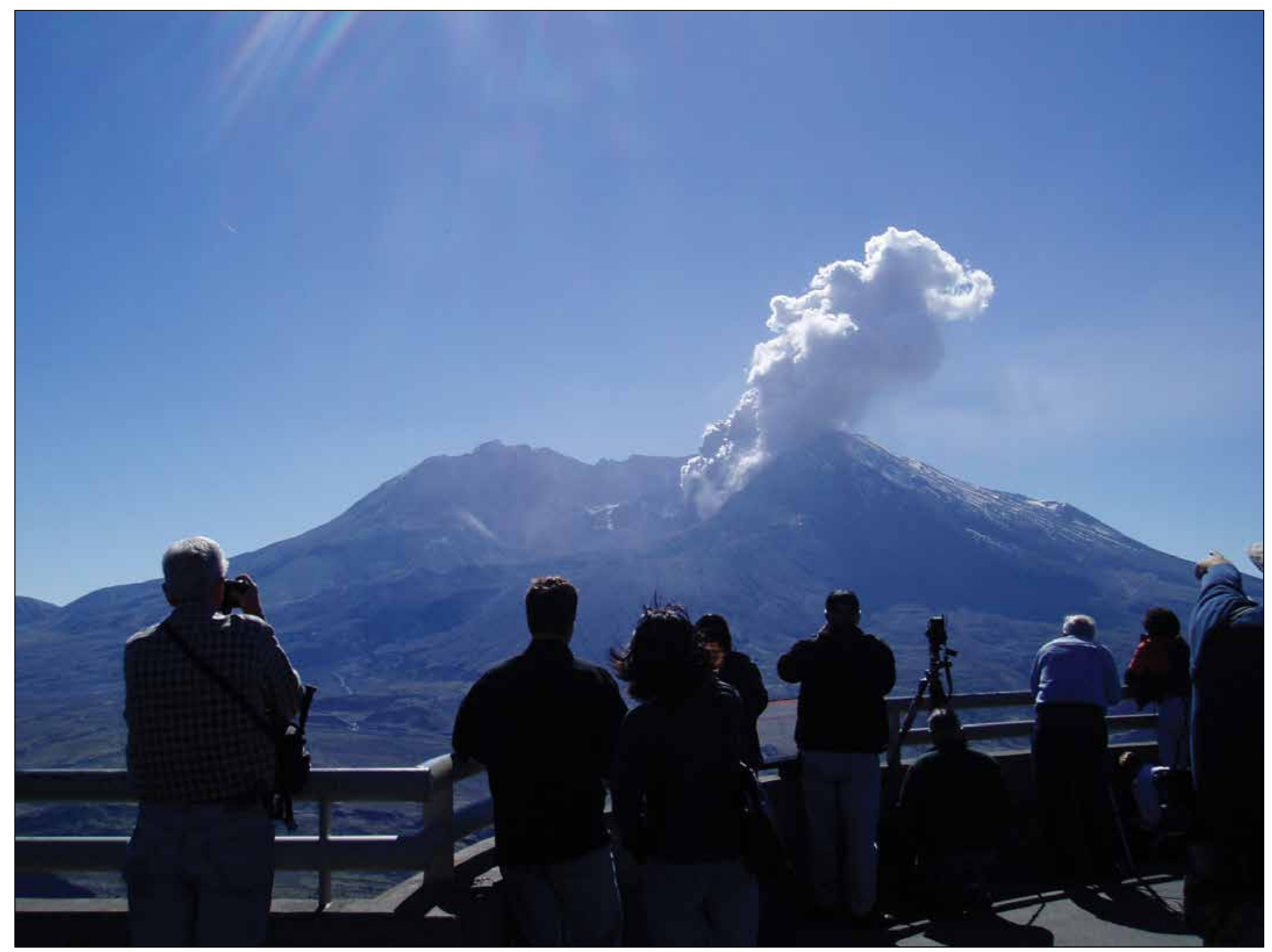

Visitors at the Johnston Ridge Observatory, 5 miles north of the crater, observe some of the first steam and ash explosions of the October 2004 eruption at Mount St. Helens, Washington. USGS photograph by Gene Iwatsubo, October 1, 2004. 



\section{Appendix 1. CVO Personnel and Other Contact Information}

The following templates list members of the communications teams responding to a news media-intense event. Personnel include U.S. Geological Survey (USGS) Cascades Volcano Observatory (CVO), Volcano Science Center (VSC), Volcano Hazards Program (VHP), and Office of Communications and Publishing (OCAP) communications staff and key decisionmakers who will provide input on messaging and be responsible for informing other agencies and partners. The list is for internal-use only and should not be distributed to the news media or public. For front desk personnel and guest colleagues include other relevant information such as how to transfer internal CVO telephone calls, listen to voicemail, record a new voicemail greeting, make announcements over the CVO building intercom system, and contact security.

\section{U.S. Geological Survey Cascades Volcano Observatory communications team}

[CVO, Cascades Volcano Observatory; GIS, geographic information system;

\begin{tabular}{|l|l|l|l|l|}
\hline \multicolumn{1}{|c|}{ CV0 personnel } & Name(s) & Email(s) & Office phone(s) & Cell phone(s) \\
\hline Scientist-in-charge & & & & \\
\hline $\begin{array}{l}\text { Communications/ } \\
\text { media/outreach }\end{array}$ & & & & \\
\hline GIS/maps & & & & \\
\hline Graphics & & & & \\
\hline Social media ambassadors & & & & \\
\hline Video/archives & & & & \\
\hline Website programmer & & & & \\
\hline Website content & & & \\
\hline Security & & & \\
\hline
\end{tabular}

Offsite U.S. Geological Survey communications team

[OCAP, Office of Communications and Publishing; VHP, Volcano Hazards Program; VSC, Volcano Science Center]

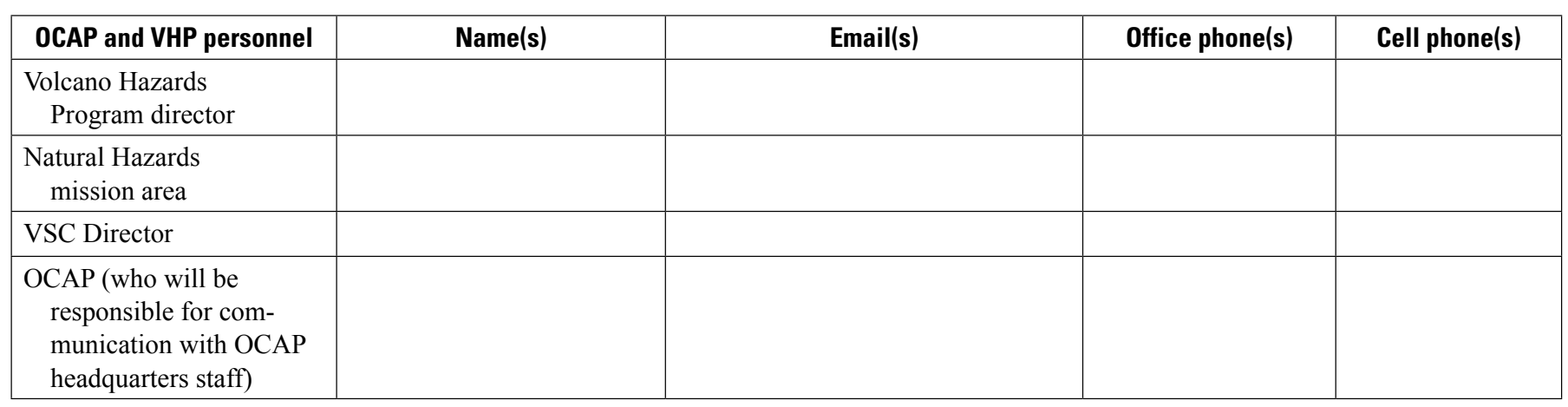

How to transfer internal CVO telephone calls:

How to listen to voicemail:

How to record a new voicemail greeting:

How to make announcements over the building intercom system:

Guidance about building security: 



\section{Appendix 2. Single Overriding Communication Objective Worksheet}

A single overriding communication objective (SOCO) worksheet helps identify the most important objective or desired outcome of your communication. The SOCO worksheet can be used for all communication with the public and partners, including briefings and news releases.

\section{Single Overriding Communication Objective (SOCO) Worksheet}

\section{Target Audience:}

Who is the main audience or population segment you would like to receive this information?

- Primary

- Secondary

\section{Objective:}

What is the one message that the audienceshould take away from this interview/story/ or product?

\section{Key Messages:}

Write a statement that reflects the key messages that you would like to see as the lead paragraph in a newspaper story or broadcast news report

\section{Key Facts:}

What are several facts or statistics you would like your audience to remember as a result of reading or hearing about this story?

1.

2.

3.

\section{Primary Contact:}

Who will serve as the primary point contact?

Name:

Contact information:

Date and time of availability:

The Single Overriding Communication Objective (SOCO) worksheet was developed by the Centers for Disease Control and Prevention and is used frequently in health-hazard communication. Use the SOCO to identify top objectives and to prioritize messages for interviews, communication plans, and communication products for the public. 


\section{Directions for Developing a SOCO}

Use the following guiding questions to develop your communication objectives. As the situation changes, re-evaluate the worksheet and update the messages.

\section{Target Audience}

Who is the main audience or population segment you would like this message to reach? Who is the secondary audience? Are there other groups that will be interested in your communication but who are not part of your targeted audiences?

\section{Key Message}

In one brief paragraph, state the key point or objective you want to communicate. Consider a statement that you would be feel comfortable with when you see it as the lead paragraph in a news story.

\section{Key Facts}

What are the three most important facts you need an individual to understand about your issue?

\section{Objective}

What is the one message or action someone needs to understand? What is your take-home point?

\section{Primary Contact}

Review your schedule and confer with the primary point of contact to choose a time to release the information when staff are available to answer questions. 


\section{Appendix 3. Communication Plan Template}

A communication plan helps you and your team develop a strategy for achieving a multistep plan with different products or activities, multiple spokespeople and external partners, diverse audiences, and controversial or sensitive issues. A communication plan is ideally created as a document that can be shared, edited, updated, and consulted by team members while the plan is in effect. It is also useful as documentation after the conclusion of the event, to assess what was effective and what was not and to guide future plans.

\section{Title}

[Indicate the title of the plan, whether it is for a specific product, project, program.]

Goal(s) of the Plan

Metrics for Assessing Effectiveness of the Plan

Target Audiences

\section{Plan Members}

Plan members: U.S. Geological Survey internal staff

\begin{tabular}{|l|l|l|l|}
\hline Affiliation/position & Contact name & Office and cell phone & Email \\
\hline & & & \\
\hline & & & \\
\hline
\end{tabular}

Plan members: external partners or agencies

\begin{tabular}{|l|l|l|l|}
\hline Affiliation & Contact name & Office and cell phone & Email \\
\hline & & & \\
\hline & & & \\
\hline
\end{tabular}

\section{Messaging}

[Add your single overriding communication objective (SOCO) and supporting messages here.]

\section{Controversial and (or) Sensitive Issues}




\section{Spokespeople}

Spokespeople

\begin{tabular}{|l|l|l|l|l|}
\hline Spokesperson & Subject matter & Office phone & Cell phone & Email \\
\hline & & & & \\
\hline & & & & \\
\hline
\end{tabular}

Products for Press Kit (FAQs, maps, graphics, etc.)

Activities (Website Stories, Social Media, Media Day, Public Meetings, or Events)

Background Information

Resources to Aid in Understanding (Web, Fact Sheets, Photographs, Videos)

\section{Action Plan}

Action plan and strategy to communicate U.S. Geological Survey research activity

[Dates are approximate]

\begin{tabular}{|l|l|l|l|l|l|}
\hline Date & Activity & Description & Notes & $\begin{array}{c}\text { Congressional } \\
\text { notification? }\end{array}$ & Lead/contact \\
\hline & & & & & \\
\hline & & & & & \\
\hline
\end{tabular}

\section{Summary of Results}

[Provide links, news clips of stories, event summaries.] 


\section{Appendix 4. Talking Points and Key Messages}

Talking points are short and simple statements that contain all of the relevant information you want to convey to the news media and the public. When writing talking points, begin with the skeletal information and be prepared to flesh it out as the event progresses. Talking points will be most effective if they put current activity in perspective, show relevance to people, are supported with evidence and examples (proof points), and are written as memorable quotes. When possible, use visuals, statistics, and other tangibles to support your points. Identify and polish the highest priority talking points as key messages for placement in public documents such as press releases or for easy verbal delivery.

Talking points and other products, such as images, videos, and updates can be provided internally using a shareable electronic platform such as an internal-use shared drive. It is imperative that all spokespeople use the same talking points and convey the same information. Talking points and key messages can change, so include the time and date on them and check back with management and scientists periodically.

\section{Key Components of Talking Points}

In general during an event, talking points should answer "What is happening," "What is the impact," and "What are we doing about it." As the situation evolves, talking points might include:

- Description of general physical processes in action.

- Affected area and the size of the event.

- Descriptions of potential impacts to affected areas.

- U.S. Geological Survey (USGS) monitoring of the situation.

- Names of other agencies who are responding to the event.

- Significance and uniqueness of the event.

- Most likely scenario or range of activity.

-What events scientists expect next.

- Dates and locations of most recent and (or) similar activity.

- Communication mechanisms by which people can maintain situational awareness - where to get up-todate, reliable information.

\section{Eruption and Hazards Messages}

The USGS is tasked with providing information about the status of the volcano and potential impacts, and not with providing guidance for mitigation. Below, are commonly acknowledged key messages that officials might provide for the safety of their constituents. For detailed and up-to-date information, see the USGS Volcano Science Center (VSC) web pages about hazards (https://www.usgs.gov/natural-hazards/volcano-hazards/ understanding-volcanic-hazards-can-save-lives).

\section{Preparing for a Volcanic Eruption}

Become aware of the volcano hazards that might affect the areas where you live, work, or visit. Make a plan and ensure everyone in your family knows what to do in case of an emergency and how you will communicate (see https://www.usgs.gov/natural-hazards/volcano-hazards/ be-informed-make-a-plan-build-a-kit).

\section{During a Volcanic Eruption}

Follow recommendations of local authorities and emergency officials.

\section{On a Volcano}

You may be at risk from falling ash and volcanic rocks, lava flows, lahars, volcanic gases, and fast-moving torrents of hot rock and gas (pyroclastic flows).

- Follow instructions for exiting the area as fast and safely possible.

- Stay aware. Your route to safety may be cut off. If you are on a snow- and ice-covered volcano, stay off valley floors and out of low-lying areas-lahars (volcanic mudflows) may occur.

- Pay attention to closure signs; they can save your life.

\section{Near or Downstream of a Volcano}

You may be at risk from lahars (volcanic mudflows).

- Listen carefully to official reports via emergency broadcasts.

- If officials warn of an approaching lahar, seek high ground off the valley floor as quickly as possible, such as by moving up a hillside. Then, seek shelter. 
- Evacuate if necessary.

\section{Near or Downwind of a Volcano}

You may be at risk from lava flows and falling ash.

- Follow evacuation advice from officials.

- Stay off and away from fresh lava flows - burning vegetation releases methane gas, which can accumulate in covered areas and be released as an explosion.

- Seek shelter and minimize your exposure to ash.

- Do not drive, unless absolutely necessary; ash can damage the engine, filters, and exterior of your vehicle, and driving on ash-slickened roads with reduced visibility can be hazardous. Reduce driving speed.

- Keep outside air from getting inside. Close and seal (for example, with duct tape) non-essential doors, windows, vents and other gaps. Place damp towels at the bottom of external doors. Minimize use of heating, ventilation, and air conditioning (HVAC) systems that draw in outside air.

- Listen for up-to-date reports - ash fall might be a significant hazard or only a nuisance, depending upon eruption size, style, and duration.

- Learn about ash impacts and recommendations for cleanup. (https://www.usgs.gov/natural-hazards/ volcano-hazards/ashfall-most-widespread-andfrequent-volcanic-hazard)

\section{After a Volcanic Eruption}

Actions to take after an eruptive event are dependent upon whether the eruption is continuing, the level of impact, and the type of eruption. The most important thing to do is to watch and listen for updates from local authorities; they will determine when to lift or revise evacuation orders and organize relief response.

\section{Volcano Science Center Key Messages}

When assembling key messages, focus on the topic being addressed. Some general considerations for key messages are as follows:
- First and foremost, ensure that the public understand that VSC and the Cascades Volcano Observatory (CVO) are part of the USGS. The USGS is the key organizational level for most communication.

- A 2018 threat assessment states that the United States and its Territories are home to 161 active and potentially active volcanoes (Ewert and others, 2018).

- Between 1980 and 2018, the USGS reported 120 eruptions and 52 episodes of notable volcanic unrest (increased seismicity, observed ground deformation, gas emission, individually or in some combination) at 44 U.S. volcanoes.

- The volcanoes have the potential to erupt again; millions of our citizens and our critical infrastructure is at risk from volcanic eruptions.

- Volcanic eruptions can have regional, national, and international consequences.

- Volcanic disasters are preventable. With knowledge, preparation, and early warning, individuals and communities can live safely with volcanoes.

- Volcano monitoring is key to risk reduction. The USGS' capability to assess and mitigate volcano hazards depends on its ability to assess volcano hazards; monitor volcanoes with instrumented networks, new technology, and satellites; research volcano processes; and communicate hazard information and warnings to the public.

- Placing volcano monitoring instruments on volcanoes in advance of eruptions allows scientists to obtain long-term data sets and to identify the signs of volcanic reawakening.

- Volcanoes usually give warning signs that they will erupt. USGS scientists have developed a forecasting system to alert public officials and the general public to the possibility that a volcano may erupt.

- Adequate volcano assessment, monitoring, and instrumentation leads to more efficient warning to the public of impending danger and therefore helps mitigate risk and safeguard society.

- The USGS and its partners work in cooperation with Federal, State, and local authorities and the media to provide warnings about volcano hazards. 


\section{General CVO Messages}

These Cascade volcano-specific messages demonstrate the meaning and relevance of volcanic eruptions to humans.

- In recent centuries, most volcanoes of the Cascade Range have shown signs of being "active" (seismically and geothermically active, eruptions in recent centuries, or tectonically poised for magma formation) and, although are not currently erupting, have the potential to erupt again.

- As population increases in the Pacific Northwest, areas near volcanoes are being developed and recreational usage is expanding. As a result, more people and property are at risk. The next eruption in the Cascade Range could affect hundreds of thousands of people.

- With virtual certainty, Cascade volcanoes will erupt again. When they do, ash may travel on the wind for many miles, affecting distant communities and disrupting air travel. At the volcano, the melting of snow and ice can cause lahars (volcanic mudflows) that travel down river channels to areas distant from the volcano. In some cases, lava flows will be the main hazard; in other areas, explosive activity might produce various hazards (for example, ashfall, ballistics or pyroclastic density currents).

- Volcanoes show signs that they are going to erupt days to months or more in advance. Rising magma shakes and deforms the Earth, and emits volcanic gases. Scientists measure earthquakes, ground surface deformation, changes in gas flux and composition from vents and cracks, and other physical changes.
- With adequate monitoring instrumentation and surveillance, staff at CVO can detect volcanic unrest and provide warnings of possible eruptions, thus allowing communities and others at risk to prepare.

- Scientists are engaged in studies of how volcanoes work; they develop and install instruments that detect volcanic unrest; they explore new methods for predicting eruptions; and they communicate this information to officials with responsibilities for community safety.

- Scientists evaluate hazards by examining evidence of previous eruptions and identifying areas likely to be affected by future eruptions. This provides a basis for mitigating effects of future eruptions.

- Scientists study volcanoes to develop and test new ideas about how volcanoes function; to develop new instrumentation; and to improve eruption-forecasting models so that they can provide timely warning to officials and residents in areas at risk.

- CVO aids Federal, State, and local authorities in developing jurisdictional emergency coordination plans and outreach.

- CVO works in cooperation with Federal, State, and local authorities and the news media to provide warnings about volcano hazards.

- Science isn't "done" until it's shared. Scientists provide information about volcanoes and hazards to public officials and the news media so that they can inform land use and emergency planners, the Federal Aviation Administration and other Federal agencies, schools, and the public.

"When your choice of words is memorable, clever, or unexpected, almost guaranteeing that it will be used, you're 66 talking in "sound bites." A sound bite is a short, catchy snippet of speech that captures the essence of your message in a way that stands out in your audience's memory." Most situations benefit from an attitude of compassion and confidence - compassion with the opposing view or the victims, confidence that you will be doing the right thing."

99 -Beckwith, 2006 



\section{Appendix 5. Examples of News Releases}

A news media release is a short, official statement about current conditions. News releases indicate what is new, how or why conditions have changed, the impact of the changes, and how the U.S. Geological Survey (USGS) is addressing the situation. The news media release can include a brief background, prognosis, and description of hazards, along with links for more information. Two examples of news media releases are provided below. Visit the U.S. Geological Survey (USGS) Office of Communications and Publishing (OCAP) internal web page for specific and up-to-date guidance about writing news releases and advisories.

\section{Sample of a News Release that Might Accompany an Official Alert Level Change}

\section{Logo}

Title

Release date and time

\section{States what is new and the} meaning of the change

Describes why the Alert Level has changed

Describes how the USGS is addressing the situation

\section{Role of the USGS}

Location of additional information

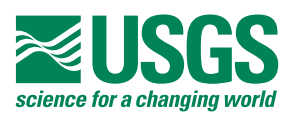

USGS raises alert level at Mount St. Helens

Released: 00/00/0000 8:04:21 a.m.

Scientists at the U.S. Geological Survey (USGS) have raised the Volcano Alert Level for Mount St. Helens from Normal to Advisory. This change in alert level indicates that the volcano is exhibiting signs of elevated unrest above known background level.

Approximately fifty earthquakes over magnitude 1.0 have been recorded. A magnitude 3.4 earthquake yesterday was centered two miles west of the volcano and was reported as felt in the vicinity of the volcano.

Scientists at the USGS and Pacific Northwest Seismic Network are placing temporary sensors around the volcano to augment the existing monitoring network.

The USGS is responsible for issuing timely warnings of potential volcanic disasters to affected communities and civil authorities.

Learn more about the Volcano Notification Service and Notification Types at the USGS Volcano Hazards Program website (https://usgs.gov/ volcano-notifications). Volcano Updates are available at https://www.usgs. gov/natural-hazards/volcano-hazards/volcano-updates and through social media such as USGS Volcanoes on Facebook (https://www.facebook. com/USGSVolcanoes/), USGS Volcanoes on Twitter (https://twitter.com/ USGSvolcanoes), and USGS Volcanoes Instagram (https://www.instagram. com/usgsvolcanoes/). Register to receive Volcano Updates through the Volcano Notification Service (https://volcanoes.usgs.gov/vns2/). 


\section{Example of a News Release that Describes Ongoing Activity, Hazards, and Role of the USGS}

Logos

Title

Release date and time

States what is new and the meaning of the change

Describes current work of scientists to track progress of the eruption

Quote by USGS authority about the hazard that could be used in a news story

Perspective offered in overviewof recent activity and community impacts

Describes impacts to monitoring instruments

\section{Prognosis and description} of hazards

Background information

\section{Role of the USGS}

Location of additional information
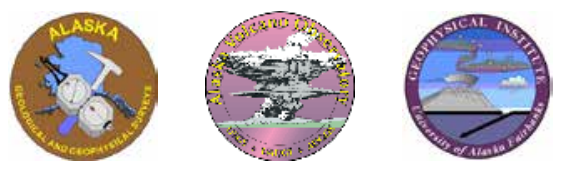

\section{USGS Tracks Explosive Eruption of Okmok Volcano in Alaska} Released: 7/18/2008 5:58:27 p.m.

Anchorage, AK-Okmok Volcano in Alaska continues to produce explosions and ash plumes through a newly created vent and poses hazards to air travel in the area.

Scientists are using a combination of seismic and GPS instruments on the ground and weather and radar satellites in space to track the progress of the eruption. Human visual observations are limited because airborne ash obscures a view of what is happening inside the volcano's 6-mile-diameter caldera and the area is too hazardous to enter.

"We are dealing with a scientific challenge because the volcano went from very quiet to a large eruption, putting ash to high altitudes with almost no warning," said John Power, Acting Scientist-in-Charge of the Alaska Volcano Observatory (AVO)

The powerful eruption in the Eastern Aleutian Islands began unexpectedly on July 12 , sending up a wet, ash and gas-rich plume that reached an altitude of 50,000 ft above sea level. Heavy ash fall occurred on eastern Umnak Island. A dusting of ash fell in the busy fishing community of Unalaska, 65 miles northeast of Okmok volcano. The ash plume soon spanned several hundred miles across the North Pacific, causing many trans-Pacific flights to be diverted and cancellation of flights to the Dutch Harbor airport. The gas cloud from the eruption is now over Montana.

The eruption also destroyed or damaged seismic and deformation sensing equipment at two monitoring stations. A third station has lost its communication pathway due to destruction at the other two. Seismic equipment relays earthquake information and GPS equipment is used in monitoring the deformation of the ground surface in response to magma movement. Seven seismic stations are still operational and seismicity has gradually decreased in intensity since the initial eruption.

At a minimum, activity at Okmok is likely to continue for days or weeks. Strong gas-driven explosions can produce rock ballistics or larger volcanic debris that can be hurled beyond the crater rim of the volcanic caldera, potentially landing in surrounding areas several miles away. Fast moving clouds of ash, larger debris, and hot gas can form and flow across the caldera floor, rise up over the caldera wall and continue to flow down Okmok's flanks. Rain mixed with ash could create mudflows and rapid flooding along island drainages. As soon as conditions allow, AVO scientists will travel to the volcano in order to document and understand the sudden onset of explosive activity and repair damage to monitoring equipment.

The Okmok caldera formed during catastrophic eruptions 12,000 and 2,000 years ago. There are about a dozen cones within the modern caldera that formed in the last 2000 years, and the most recent eruptive activity occurred in 1945, 1958 and 1997.

One violent eruption of Okmok in 1817 produced many feet of ash and "scoria" rock debris on the northeastern caldera rim, as well as ash fall on Unalaska Island and floods that buried an Aleut village at Cape Tanak on the northeast Bering Sea Coast of Umnak Island.

USGS is responsible for issuing timely warnings of potential volcanic disasters to affected communities and civil authorities.

Information about the current eruption of Okmok Volcano, including activity statements, images, background materials, and related hazards can be found at the AVO home page and the AVO Okmok Activity web page

The Preliminary volcano-hazard assessment for Okmok Volcano, Umnak Island, Alaska is available. 


\section{Appendix 6. General Guidance for Working with News Media}

The U.S. Geological Survey (USGS) Cascades Volcano Observatory (CVO) relies on the news media to provide accurate and up-to-date information to the public. Because of the important function that the local news media can play in distributing hazard information to affected communities during a crisis, CVO (along with many other agencies) may provide local media priority over national and international outlets.

This guidance for working with the news media is derived from Federal Emergency Management Agency (FEMA) Course G-290-Basic Publication Information Officer.

\section{General Considerations for News Interviews}

In news interviews, both the interviewer and interviewee have jobs to do. Your job is to represent the USGS well; a reporter's job is to get a good story. With preparation, you can ensure that both objectives are fulfilled. Some general

considerations for news interviews are as follows:

\section{Look}

\section{Answer \\ the request for an \\ interview in a timely way.}

at their previous work and speak with colleagues. While no one owes an interview to the news media, consider that this might be a good opportunity to share your work.
As you make an agreement to give an interview, talk to the reporter. Understand their motives. Show the reporter that you understand their needs by asking about deadlines.

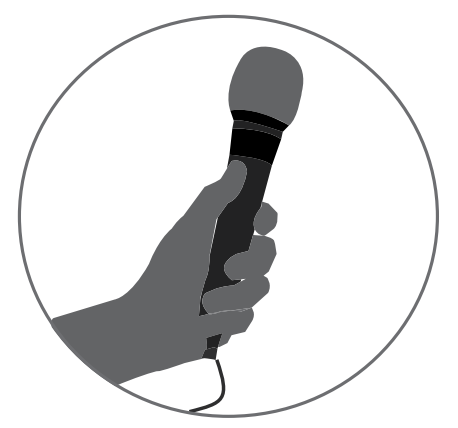

Reporters do not expect that you will only answer their questions - they might not even know if their questions are relevant. They will rely on you to tell the viewer or reader the relevant facts, how people are affected, and what's new.

When in the field, ensure that they have easy access to the site and sufficient space to work. Consider setting up at a viewing area or even a dedicated space in the parking lot so that reporters get good footage and you maintain control over the location of the interview.

"Framing is the setting of an issue within an appropriate context to achieve a desired interpretation or perspective. Framing endows certain dimensions of a complex topic with greater apparent relevance. Bring the message close to home. Make the message matter now. Frame it in terms of human health, or national security."

Shone and Marx, 2009 


\section{Preparing for News Interviews}

Your news interview will benefit from careful attention to messaging and presentation. Some general considerations for preparing for news interviews are as follows:

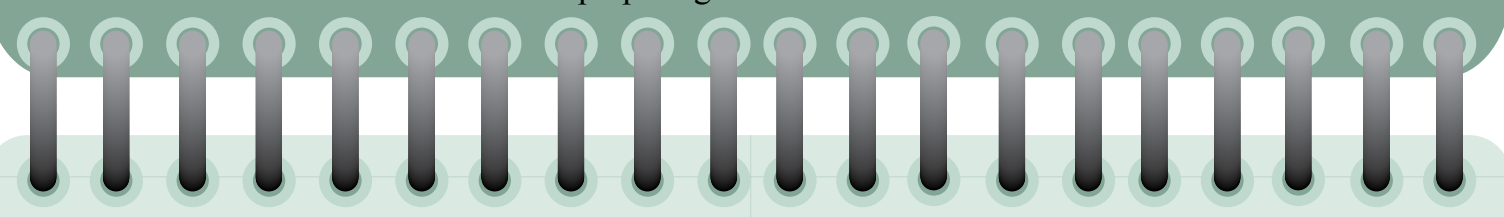

Ask the reporter about the scope and intention of the interview and request a few questions in advance. Prepare talking points. During the interview, resist the temptation to make off-the-cuff remarks

Never feel compelled to provide an interview on the spot. Talk to the reporter and settle on a mutually agreeable time. Take the time to compose yourself. News reporters commonly practice reciting their news reports and you can do the same in a quiet room. Remember the principal words of the report you want to convey-you do not need to memorize exact sentences.

Translate your science into simple terms so that you are not searching for words during the interview.

Be careful when using words that have one meaning for hazards scientists and another meaning in common usage by the public. Explain these words where appropriate. One example is

"Warning," used by the USGS as an alert level, but which also carries more ominous connotations with the public.

The public's interest is in people. Therefore, showcase the work that our personnel are doing in the public interest and its value. Human-interest stories about our personnel show the face of the USGS that often is not seen by the public. The public wants to get to know you and how you work as a scientist.

The news media and public are interested in new technologies and ideas. Remember to discuss them in addition to events at the volcano.

Giving an interview in the field requires a team effort. Permissions are required on public lands.

"The bobbing and weaving between the two modes (creativity and critical thinking) can create texture and complexity in the interview, instead of it being one-dimensional. A question is asked, the answer begins with a spark of spontaneity — a set of possible answers - and then discipline is imposed.

Q: What do you think caused the dinosaurs to go extinct?

A: Lots of ideas - could have been an asteroid, could have been climate change, could have been too much television, maybe they just got bored, I don't know, but there is a lot of evidence to suggest that one hypothesis is the most logical, which is $\mathrm{xxx}^{\prime}$

-Olson, 2009 


\section{Developing Content for News Interviews}

Choosing content starts with identifying audience needs and the messaging you seek to convey. Some general considerations for developing content for news interviews are as follows:

Choose a blend of talking points that you see as most important to convey and answers to questions that you know will be asked. This will require you also to plan some transition statements between the two. Start with the most important point. Journalists are often limited by space and may oversimplify a story to shorten it. Convey short and accurate general statements.
Lead with what you know, and not what you don't know. You are not expected to have all the answers to an interviewer's questions. Prepare yourself for those moments when you do not have the answers.
Teach about the scientific process by informing reporters about the many iterative steps required to analyze a scientific problem. Acknowledge that the new finding is just one step along the journey to a full answer. Explain what is needed to reach final understanding.
Do more than educate-give messages that are derived from the bureau mission! This can provide a more in-depth interview, and it helps you to phrase the message in terms relevant to the USGS.
Use consistent terminology that is agreed upon with colleagues prior to the interview. Introduce new terms that are necessary to understand the situation and explain the terms clearly.
You are part of the story, so talk about your work and the work of the USGS. Let the excitement of your work show. Demonstrate that USGS consists of real people. Members of the news media may ask you about how you feel, and as scientists we are inherently underprepared, so be ready. Say something useful."It makes us feel good to be able to contribute to the safety of people." Or, are you scared? "There definitely is a hazardous element to our work, and that is one reason why it is important for us to install monitoring instruments before volcanic unrest begins - to lessen our time in hazardous areas." Or, how does it feel to work there? "It IS an amazing experience to work on this volcano. The rocks, the steam, the changes going on during this eruption. It's a reminder of why we need to improve our understanding of how volcanoes work and continue our partnerships with public officials in communities at risk." Be cognizant that major events may be traumatic for some, so temper your excitement with a recognition that damage has been done.
Use values-based messaging: it communicates why our work matters and the benefits of preparedness. Examples include: "Learning about the volcano now can help your family to live responsibly and safely during a volcanic eruption"; "Preparations that you make today can save lives in your community"; and "Taking simple steps to prepare will help you to respond quickly when the volcano erupts." 


\section{Developing Content for News Interviews-Continued}

Choosing content starts with identifying audience needs and the messaging you seek to convey. Some general considerations for developing content for news interviews are as follows:

Provide the reporter with an explanation of the big picture and significant new information about the situation and the role of the agency. Prepare to speak about the implications of your research and how it is relevant to society.
Provide content that can put the current situation into context. Explain what aspects of the situation are new, how they add to our understanding of the volcano, and how this change is relevant to communities at risk.
Develop narratives that include science, the work of scientists, and impacts to people at risk.

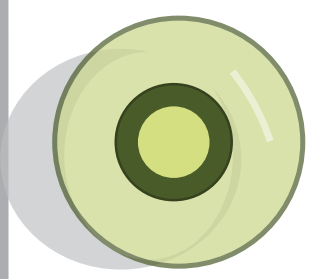

Use concrete wording and examples that can make unexperienced events feel more real.
Use comparisons to put scientific information in perspective. "The cooling lava dome resembles a steaming plate of hot food"; "Ash turned day to night, like a curtain closing between the land and sky";"Volcanologists are like detectives who sleuth around volcanoes in search of evidence of past eruption events"; "Tectonic plates fit together like giant pieces on an Earth-size jigsaw puzzle"; "An eruption plume is like a turbo-charged thunderstorm above the volcano".

Non-scientists sometimes misinterpret scientists' statements about uncertainty as admissions of errors, rather than as an integral aspect of science. It is important that the public understand uncertainty, so explain it by noting that forecasts have a range of outcomes. Provide an explanation about the sources of uncertainty. It is not helpful to say "We have no idea". It is accurate to say "Although we are unable to predict the exact timing and size of a possible future event, as specialists we agree that life-saving actions are required at this time."

Anticipate some of the images and graphics that might be required to tell the story. Consider using visuals such as graphics or photographs, physical samples or demonstrating how instruments work or how a process occurs. Double check that graphics and photographs are accurate and are of the highest resolution possible. 


\section{Conduct During News Interviews}

You can set the tone for your news interview through your attidude, appearance, and approach to answering questions. Some general considerations for conduct during news interviews are as follows:

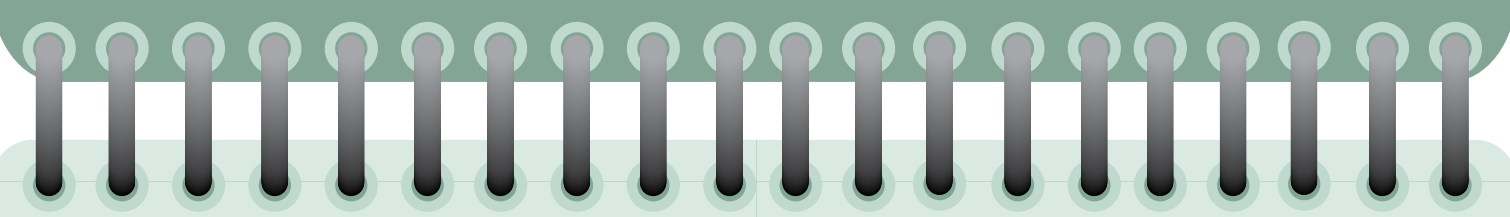

Be yourself. You don't have to be perfect, just passionate and totally in the moment. Clear your mind. Relax and be authoritative. If you are not relaxed, then you give the appearance of being in fight-orflight mode.

Show compassion and empathy for people affected by the volcanic activity. To do so, you must speak not from the brain, but from the heart.

For an on-camera interview, ask the reporter where to look, which will typically be slightly offcamera not at the camera. If you are not sure about what to do or where to look, ask for advice. The reporter is motivated to get the best audio and visual story possible and will appreciate a brief discussion about how to achieve this.

"Own" the interview. You can't control what you are asked, but you can control what you say. Have a list of your key messages in mind, and transition back to them. Make their questions relevant to your key messages. For phone interviews, or even for an informal sit-down interview, have your notes open for quick viewing.

Use the bridging examples to avoid saying "I don't know" or "No comment." (See Covello Bridging template in appendix 7.) Better phrases are "We will provide updates as more information becomes available" or "Let me put you in contact with someone who is better suited to answer that question."

Have major transition sentences ready that will take you to supporting messages. Some bridging examples include: "What is most important is..." or "What the public should know is..." (See Covello Bridging template in appendix 7.)

Don't overthink their question. If what they are asking is more complicated than a simple answer, they don't really want it. For example, if they ask "how many?" and you don't have a good number, then provide a general answer that supports the larger idea.

Include the question within your answer. This will ensure that your statements are used in context and not separated from the original questions.

For recorded (non-live) interviews, if you don't like the answer that you are giving and your answer is still in progress, then end it with an audible sound that will make the clip unusable and go back to restate your answer. This is a common practice by the media. 
After the News Interview

Follow these general considerations to build relationships with people who can broadcast your messages for you, now and in the future:

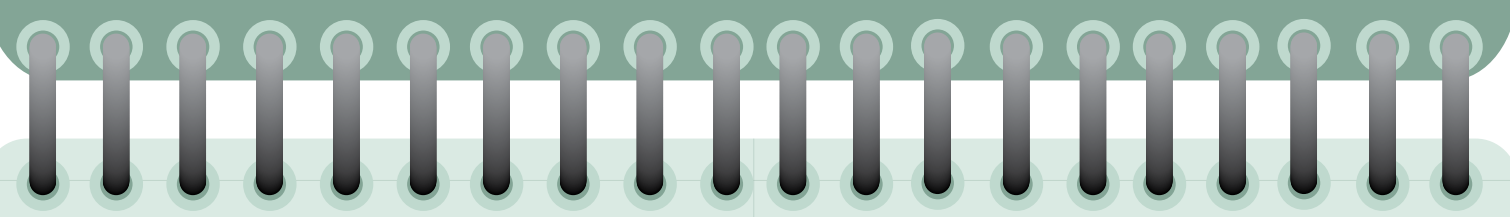

Keep in mind that reporters also are human beings, and that the same courtesies that you extend to other professional colleagues should be extended to reporters. Thank them for the opportunity to be interviewed.

Provide them with the known schedule for future updates.

Lead them to additional resources that can help them create more in-depth and interesting stories, such as links to online images, video galleries, interactive maps, or data products.

Exchange contact information to encourage follow-up questions.

After the interview has been broadcast, you may provide the interviewer with feedback. If the interview was presented well and fairly, say so. If there were errors of fact, point them out in a helpful way. Most reporters want to get the story right and will appreciate corrections if they are offered in a positive manner - there might be an opportunity to correct the errors in a future broadcast. If the reporter is not responsive and the errors are egregious, contact the editor and explain your position.

\section{News Interviews Involving Multiple Agencies}

During a volcanic crisis, CVO may be called upon to participate in a media conference that includes multiple agencies. It is important that all participants understand that the most effective and accurate communication occurs when each agency partner stays within the purview of their expertisetheir information lane. For example, CVO staff provide information about volcanic processes, histories, hazards, monitoring and status, research, and information and training resources, as well as reports of collaborative work accomplished with other agencies, general mitigation measures used globally, and the roles of the USGS. External partners might communicate about the specifics of preparedness measures and mitigation plans, specific guidance about eruption avoidance such as evacuations and sheltering, current eruption impacts, and the locations of emergency information resources. Each agency should create its own communication objectives and messages. 


\section{Appendix 7. Covello's Risk Communication Templates}

When speaking to the news media, have major transition sentences ready that will take you to your supporting messages. Some bridging examples are provided in Vincent T. Covello's "Pocket Guide—Risk Communication Tools and Templates" (http://www.procommunicator.com/wp-content/upLoads/2012/04/risk-comm-pocket-guide-covello.pdf). 


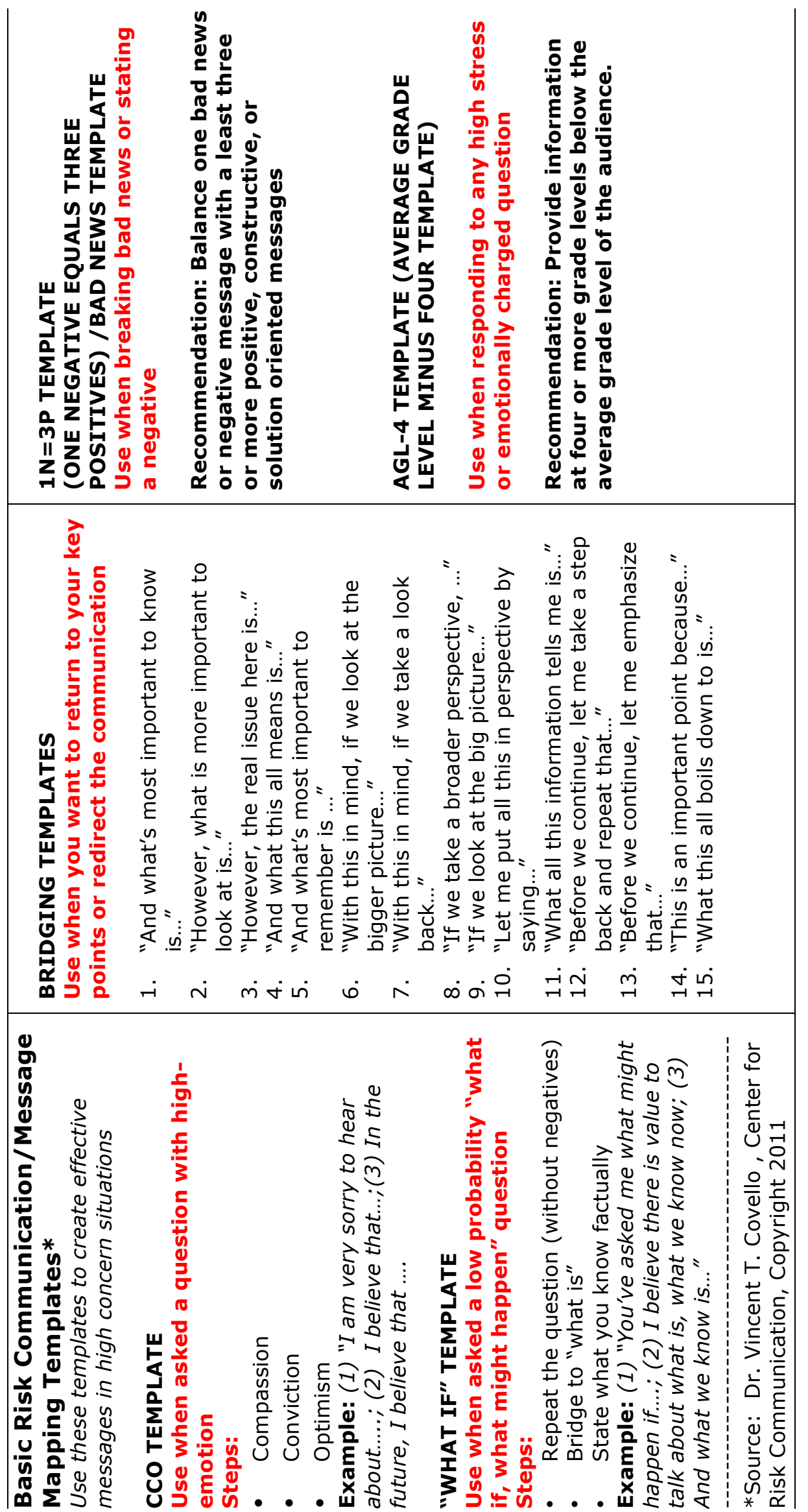




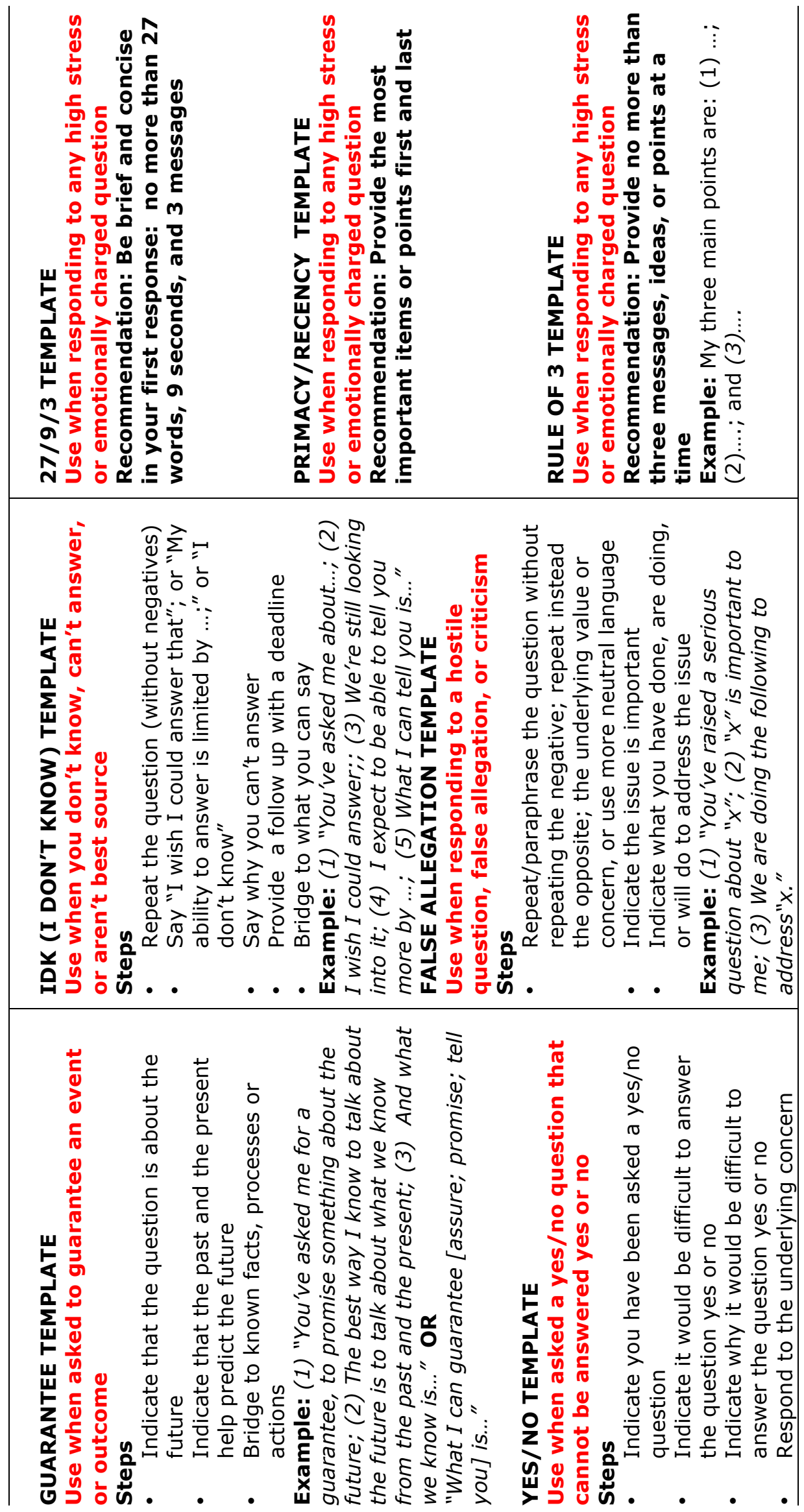





\section{Appendix 8. Documentary Request Form}

Production companies should fill out the U.S. Geological Survey (USGS) Cascades Volcano Observatory (CVO)

Documentary Request Form when requesting access to CVO facilities or an interview with CVO scientists for for television and film documentaries. The CVO Documentary Request Form is available online from the CVO Media Resources web page https://usgs.gov/cvo-media-resources.

\section{Engaging CVO Staff in Documentary Productions}

CVO staff require detailed information from filmmakers before they can agree to participate in documentaries. The type of information needed is shown in the form below, which can be used as a template.

\section{Example documentary request form for U.S. Geological Survey involvement in productions.}

[USGS, U.S. Geological Survey]

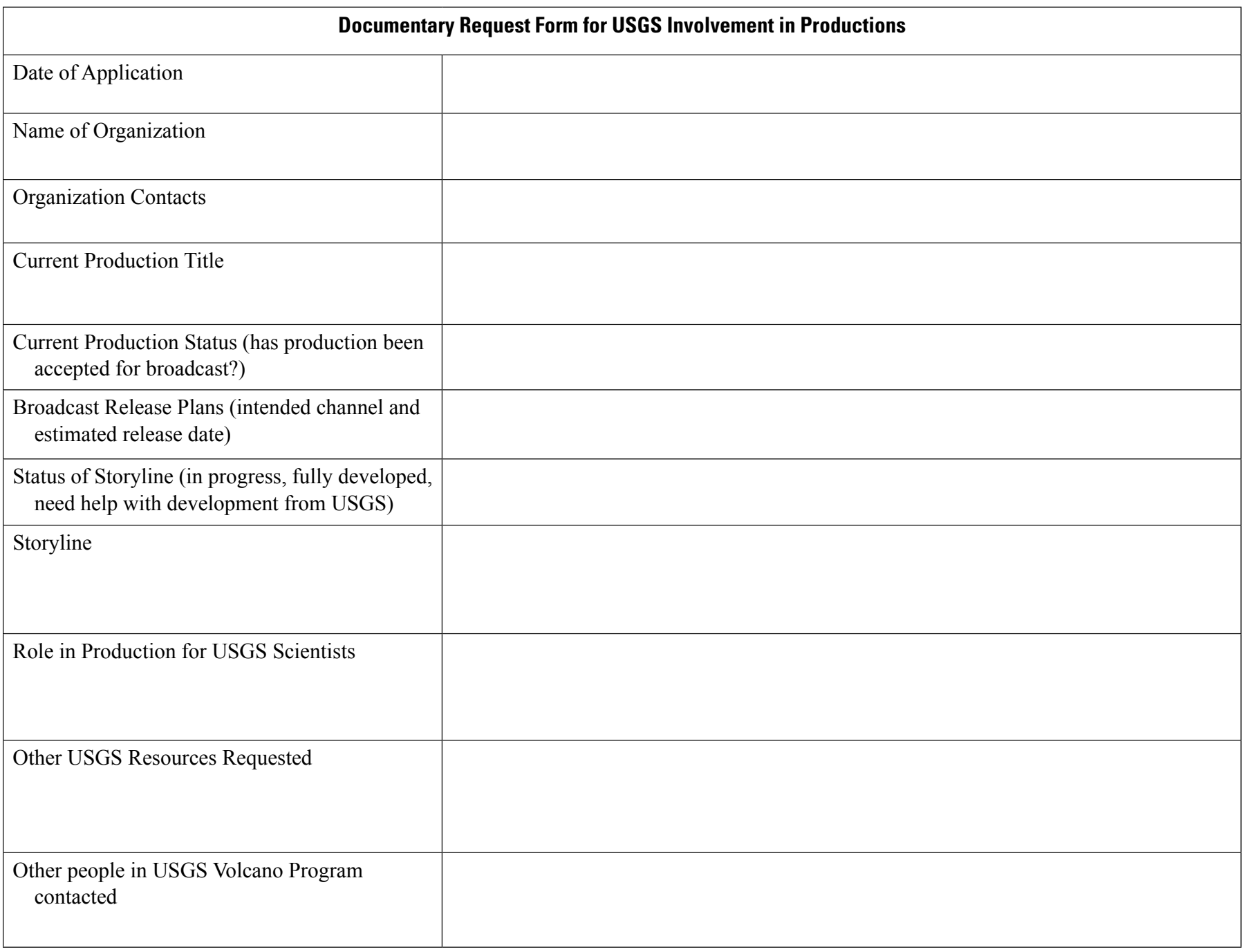





\section{Appendix 9. General Guidance Regarding the U.S. Geological Survey Cascades Volcano Observatory Website}

The U.S. Geological Survey (USGS) Cascades Volcano Observatory (CVO) website provides background information on volcanoes and volcano monitoring, official updates and notices, multimedia image galleries and videos, and contact information. The intended audience for website content includes the news media, affected communities, other agencies and partners, and the general public. During times of heightened news media interest, additional web pages may be created.

\section{Activity Updates}

Staff post activity updates and information statements on the CVO Volcano Updates web page, https://www.usgs.gov/ natural-hazards/volcano-hazards/volcano-updates.

This information is also circulated via email to members of the public who have subscribed to the Volcano Notification Service (VNS). The VNS is a free service that sends notification emails about volcanic activity happening at monitored U.S. volcanoes. The VNS can be customized by the user to deliver notifications for certain volcanoes or a range of volcanoes. Instructions for signing up are available at https://volcanoes.usgs.gov/vns2/.

\section{News Current Events and Volcano Hazards Program News}

The CVO news posts (https://usgs.gov/cvo) include current events, publications, resources, opportunities, monitoring information, and other graphics, images, or video of current activity. Links send users to web pages with more information.

Similar information is provided on the USGS Volcano Hazards Program (VHP) News web page as needed (https:// www.usgs.gov/natural-hazards/volcano-hazards/news).

\section{Media Resources}

This page contains contact information for communications specialists (https://usgs.gov/cvo-media-resources), along with links to other pages of interest, including the most recent USGS Volcano Update, alert levels, fact sheets, Cascade volcanoes FAQs, media trainings, and media operations during volcanic unrest and eruptions.

\section{Event Page}

An event web page may be created during times of intense news media interest. Components of the page may include the following:

- Chronology of Events.

- Map.

- Alert level and color code.

- Links to Updates (Volcano Activity Notice [VAN] or Volcano Observatory Notice for Aviation [VONA]).

- Brief text update.

- Monitoring data such as ashfall forecasts or seismic data

- Links to multimedia galleries, images, videos, preparedness information, geologic history, publications, or other key scientific partner, land-management, or emergencymanagement agencies involved in a response.

\section{Images and Video}

Images and videos, along with appropriate metadata, are posted in full resolution and available for download on a multimedia web page. The link(s) to a multimedia web page will be provided on the event, CVO News, and VHP News web pages.

USGS work, including photographs and videos, are in the public domain and may be used without restriction. News media and members of the public can use images and graphics from the CVO and VHP websites with credit that the graphic was provided "courtesy of the U.S. Geological Survey." No material will be provided to reporters unless it has been reviewed and approved (see USGS Fundamental Science Practices [USGS, 2019]).

Note that some non-USGS photographs, images, and graphics are used by the USGS with permission from an outside copyright holder. To use these copyrighted materials, the news media must obtain permission from the copyright holder under copyright law.

\section{Responding to Webmaster Inquiries}

Questions and comments addressed to the webmaster will be forwarded via email to appropriate CVO staff for response. Responses will be archived in a shared internal-use shared drive document. Website personnel and the webmaster are typically available during business hours. Hours may be expanded during periods of intense media interest. 



\section{Appendix 10. General Guidance for Working with Social Media}

Social media is integral to news media response and to the U.S. Geological Survey (USGS) Cascades Volcano Observatory (CVO) risk communication strategy. Social media, together with other channels of communication, informs and educates affected communities about hazards and engages a broad audience interested in volcanoes. Social media provides a public forum for asking questions of subjectmatter experts that can counter misinformation and rumor. Social media enhances the CVO role in monitoring volcanoes by pushing accurate, up-to-date content as it becomes available, improving situational awareness, and ultimately, developing appropriate responses to volcano hazards. This information may in turn be amplified to broader populations by external social media users.

\section{Social Media Platforms}

The USGS has social media accounts at different levels within the organization. For example, there are social media accounts at the bureau, program, and State level and accounts for different subjects, such as volcanoes.

Volcano information, including text alerts, analysis, images, and video, will be posted to the USGS Volcanoes Facebook, USGS Volcanoes Twitter and USGS Volcanoes Instagram accounts. Other social media accounts may be created or platforms used if needed to convey information to appropriate audiences. The USGS Volcanoes posts may be shared with bureau-wide USGS social media accounts, such as the USGS and USGS Natural Hazards social media accounts, as appropriate.

\section{Target Audience}

The intended audience for social media content includes the news media, affected communities, other agencies and partners, and the general public. The media and other agencies are encouraged to share our content.

\section{Social Media Ambassadors}

A small group of USGS employees are trained to act as social media ambassadors. The social media ambassadors are authorized to post information to social media accounts and respond to comments. Other USGS staff can be called upon to submit content, which will then be edited and posted by the social media ambassadors.

Social media ambassadors will participate in development of any communication plan, talking points, and media news products. Social media ambassadors will support a unified message and be of one voice on all social media channels. Social media ambassadors will coordinate with social media representatives from other agencies and partners on the release of information and content sharing.

A shared internal-use drive folder will be created and shared among social media ambassadors, communications staff, and the scientist-in-charge. The folder will include a working file for developing new posts and an archive file for saving published posts. A file for frequently asked questions (FAQs) will also be created in the shared internal-use drive folder and used in responding to comments.

Hours when social media ambassadors will respond to comments will be determined at the time of the event; they are typically from 9 a.m. to 5 p.m., Monday through Friday.

\section{Social Media Posts-Content Creation}

Social media ambassadors develop content to support the overall media communication strategy. Social media content, which includes alerts, status reports, short explanations, and analysis of USGS activities, provides users with information from a reliable source that can be accessed on both computers and mobile devices. It enables users to stay involved and current with near real-time information and updates that can be easily shared with others.

Volcano Notification Service (VNS) alerts are posted automatically to the appropriate social media platforms. VNS includes status changes at the volcano and information statements.

Posts can include updates from the field, changes in activity, new research, news media releases, or general information. Posts will be brief and include visual materials such as images, videos, and graphics. To maintain brevity, an individual post will address a single concept or issue, which is summarized in the first sentence of the post. Posts will include links to USGS websites for more detailed information.

Unique hashtag(s) will be created and used for each event. Hashtags will be short and may be created around the form of \#[Location][Event][Date]. Hashtags of \#usgs, \#cvo, \#cascadesvolcanoobservatory, and \#[volcanoname] will also be used, along with hashtags created by other entities, if appropriate.

Periodically, live events may be broadcast on social media platforms such as Facebook Live. These events will feature scientific personnel who can provide information and respond to questions via direct interaction or live chat. The date, time, link, and topic of discussion will be provided on USGS Volcanoes Facebook, USGS Volcanoes Twitter, and USGS Volcanoes Instagram accounts.

A Facebook Note on the USGS Volcanoes Facebook page can be created at the beginning of the event. The note will be updated to provide an online chronicle of events. Frequently asked social media questions can also be developed and posted. 
Videos posted to social media will also be made available on the CVO website, the USGS Multimedia Gallery (https://www.usgs.gov/products/multimedia-gallery/videos), or the USGS YouTube Channel (https://www.youtube.com/ user/usgs).

Content from other monitoring agencies or emergency officials' social media accounts or links to their websites may also be shared to amplify official messages about closures, evacuations, relief, and recovery.

\section{Responses to Comments}

Social media ambassadors respond to social comments and messages regularly. During staffed periods, social media accounts are continuously monitored. Social media ambassadors may forward questions to subject-matter experts or use FAQs to develop responses. If a public commenter seeks information that is of value to others, consideration will be given to responding in a new USGS comment (or new post) rather than replying to the individual comment as anyone writing a comment can delete it, which also deletes the reply.

Individual comments seeking information about topics outside of the USGS field of expertise will be directed to other agencies or partners. A USGS response will direct the person making the comment to ask the question of the other agency. The social media ambassador will also work with other agencies via email or other means to let them know about comments.

Responses to comments will be archived in a shared internal-use shared drive document. Comments and public feedback may be circulated internally and used to evaluate and adjust messages, as necessary. Content may be used to prepare FAQs or additional social media posts. 


\section{Appendix 11. Volcano Science Center Rapid Reference Guide}

Guidance on what to do during the first few moments of any event are provided in the Volcano Rapid Reference Guide and posted in prominent locations in the observatory. The template in figure 11.1 can be used to create a Rapid Reference Guide for your agency.

\section{Volcano Rapid Response Reference Page}

\section{TASKS - First 10 MINUTES of volcanic event}

\section{1 - Before Speaking To Media:}

Visit operations room-obtain three known facts about situation for the development of talking points:

What Is Happening? $\longrightarrow$ (Example -At 5:25 p.m. a small puff of steam rose...and is ongoing).

What Is The Impact? $\longrightarrow$ (Example -Ash from plume will fall east of volcano).

What Are We Doing About It? $\longrightarrow$ (Example - USGS closely monitoring this event and advising local officials).

2 - Update Talking Points: Add some situation background.

3 - Arrange Additional Help: For liaison between operations room and outreach staff.

4 - Recorded Message: Place temporary messages on pertinent phone recorders information lines, and websites.

5 - Answer Inquiries: Keep talking points visible while providing telephone interviews; maintain a record of inquiries.

6 - Request Assistance From Other Offices/Agencies: If it appears that a media event might overwhelm staff on hand.

\section{ARRANGEMENTS - During first HOUR of volcanic event}

1 - News Briefing Arrangements: Establish time and place; announce the briefing; arrange for audio bridge; choose speakers; develop messages to greater depth and information; assemble agenda; address needs for graphics.

2 - Front Desk Duty: Arrange for staffing in evenings and early mornings as necessary.

3 - Joint Information Center (JIC) Planning: Initiate interagency arrangements as necessary.

4 - Review Personal Needs For Outreach Staff: Food, family schedules, for example.

5 - Off-Hours Arrangements: Advise duty scientists to check the front desk recorder for phone messages and respond to inquiries during nonwork hours. If inquiries require additional attention, contact outreach staff.

6 - B-Roll: Encourage scientific observers to take video that can be used for media b-roll; arrange for $b$-roll preparation and distribution.

7 - Web Site Information: Provide any necessary information about media briefings and b-roll to webmaster for b-roll preparation and distribution.

\section{Contact Information for Outreach Staff:}

Include contact information for additional help within office, within team and communication offices, and with partner agencies.

Example Volcano Rapid Response Reference guide showing steps to take immediately following the start of a volcanic event. Modified from Driedger and others, (2008). 



\section{Selected Reading}

Beckwith, S.L., 2006, Publicity for nonprofits: Chicago, Kaplan Publishing, 242 p.

Driedger, C.L, Neal, C.A., Knappenberger, T.H., Needham, D.H., Harper, R.B., Steele, W.P., 2008, Hazard information management during the autumn 2004 reawakening of Mount St. Helens volcano, Washington, in Sherrod, D.R., Scott, W.E., Stauffer, P.H., eds, A Volcano Rekindled-The Renewed Eruption of Mount St. Helens, 2004-2006: U.S. Geological Survey Professional Paper 1750, p. 505-519.

Driedger, C.L., and Scott, W.E., 2010, Volcano hazards, in Schelling, J., Nelson, D., eds., Media guidebook for natural hazards in Washington - addressing the threats of tsunamis and volcanoes: Camp Murray, Washington, Military Department Emergency Management Division, 44 p., accessed November 11, 2014, at https://mil.wa.gov/ asset/5ba42005d522e.

Ewert, J.W., Diefenbach, A.K., and Ramsey, D.W., 2018, 2018 update to the U.S. Geological Survey national volcanic threat assessment: U.S. Geological Survey Scientific Investigations Report 2018-5140, 40 p., https://doi.org/10.3133/ sir20185140.

Federal Emergency Management Agency, 2016, Course G290-Basic Public Information Officer: Federal Emergency Management Agency web page, accessed March 23, 2020 at https://raining.fema.gov/programs/pio/g290.aspx.

Frenzen, P.M., and Matarrese, M.T., 2008, Managing public and media response to a reawakening volcano-lessons from the 2004 eruptive activity of Mount St. Helens, in Sherrod, D.R., Scott, W.E., Stauffer, P.H., eds., A Volcano Rekindled-The Renewed Eruption of Mount St. Helens, 2004-2006: U.S. Geological Survey Professional Paper 1750, p. 493-503, https://doi.org/10.3133/pp1750.

Hayes, R., and Grossman, D., 2006, A scientist's guide to talking with the media-practical advice from the Union of Concerned Scientists: New Brunswick, N.J., Rutgers University Press, 194 p.

Hyer, R.N., and Covello, V.T., 2005, Effective Media Communication During Public Health Emergencies-A WHO Handbook: Geneva, World Health Organization, 138 p., http://www.who.int/csr/resources/publications/WHO $\% 20$ MEDIA\%20HANDBOOK.pdf.
Lundgren, R.E., and McMakin, A.H., 2013, Risk communication-A handbook for communicating environmental, safety, and health risks: Hoboken, N.J., John Wiley and Sons, 393 p.

Milch, K.F., Perry, S.C., and Bruce, J.L., 2020, Communicating hazards-A social science review to meet U.S. Geological Survey needs: U.S. Geological Survey Circular 1449, 67 p., https://doi.org/10.3133/cir1449.

National Academies of Science, Engineering, and Medicine, 2017, Communicating science effectively_A research agenda: Washington, D.C., The National Academies Press, $137 \mathrm{p}$.

Olson, R., 2009, Don't Be Such a Scientist_-Talking Substance in an Age of Style: Washington, D.C., Island Press, 206 p.

Parvanta, C.F., Nelson, D.E., and Harner, R.N., 2018, Public Health Communication-Critical Tools and Strategies: Burlington, Mass., Jones and Bartlett Learning, 529 p.

Perry, S.C., Blanpied, M.L., Burkett, E.R., Campbell, N.M., Carlson, A., Cox, D.A., Driedger, C.L., Eisenman, D.P., Fox-Glassman, K.T., Hoffman, S., Hoffman, S.M., Jaiswal, K.S., Jones, L.M., Luco, N., Marx, S.M., McGowan, S.M., Mileti, D.S., Moschetti, M.P., Ozman, D., Pastor, E., Petersen, M.D., Porter, K.A., Ramsey, D.W., Ritchie, L.A., Fitzpatrick, J.K., Rukstales, K.S., Sellnow, T.S., Vaughon, W.L., Wald, D.J., Wald, L.A., Wein, A., and Zarcadoolas, C., 2016, Get your science used-Six guidelines to improve your products: U.S. Geological Survey Circular 1419, 37 p., https://doi.org/10.3133/cir1419.

Sahagian, D., 2016, The Proof of Our Science Lies in the Telling - Communicating our science for the benefit of society: American Geophysical Union Editor's Vox, February 8, 2016, accessed May 25, 2019 at https://eos.org/ editors-vox/the-proof-of-our-science-lies-in-the-telling.

Shone, D., and Marx, S., 2009, The psychology of climate change communication; A guide for scientists, journalists, educators, political aides, and the interested public: New York, Columbia University Center for Climate Studies, Center for Research on Environmental Decisions, 48 p.

U.S. Geological Survey, 2019, Fundamental Science Practices: U.S. Geological Survey, accessed May 7, 2019 at https:// www.usgs.gov/about/organization/science-support/sciencequality-and-integrity/fundamental-science-practices.
Menlo Park Publishing Service Center, California Manuscript approved for publication December 17, 2019 Edited by Regan Austin

Layout and design by Kimber Petersen 


ह

?

옹

है

욜

할

氮

邑

을

के

จำ

을

응

음

关

몰

름

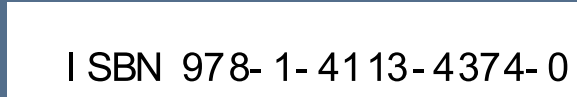

号 